\title{
AVO analyses and spectral decomposition of seismic data from four wells west of Shetland, United Kingdom
}

\author{
Nick Loizou ${ }^{1}$, Enru Liu ${ }^{2, *}$ and Mark Chapman ${ }^{2}$ \\ ${ }^{1}$ Department of Trade and Industry, 1 Victoria Street, London, SW1H OET, UK \\ (email: nick.loizou@dti.gsi.gov.uk) \\ ${ }^{2}$ British Geological Survey, Murchison House, West Mains Road, Edinburgh EH9 \\ 3LA, UK (email: eliu0103@hotmail.com; enru.liu@exxonmobil.com; \\ m.chapman@bgs.ac.uk)
}

Revised version submitted to: Petroleum Geoscience

SUMMARY: The first section of the paper principally focuses on the analysis of four wells located west of Shetland, UK, to demonstrate that the appropriate use of AVO analysis forms a worthwhile and valuable tool for exploration. The wells analysed include two with hydrocarbons, the Foinaven oil well 204/24a-2 and the Laggan gas field discovery well 206/1-2, and two wells positioned on amplitude related prospects (204/17-1 Fleet North Prospect and 204/18-1 Assynt Prospect). Both 204/17-1 and 204/18-1 failed to find hydrocarbons, where the previous work indicated mainly a Class III AVO anomaly. However, our studies demonstrate that both the amplitude anomalies conform to a Class I AVO. For the hydrocarbon-bearing reservoirs encountered in both the 204/24a-2 and 206/1-2 wells, the results confirmed the presence of Class III AVO anomalies.

A second aspect to this paper centres on the application of spectral decomposition to the seismic data relating to these four wells, which provides further evidence that there are also apparent differences in the spectral characteristics between them. Both Foinaven and Laggan exhibit Class III AVO anomalies, which

*Now at ExxonMobil Upstream Research Co., Houston, USA, enru.liu@exxonmobil.com), Tel. +1 713 4317527 
are consistent with the theoretical predictions for frequency-dependent AVO behaviours. However, the results from the 204/17-1 and 204/18-1 wells show rather complicated behaviour in the iso-frequency sections that cannot be fully explained. In summary, though the amplitude anomalies seen in the two prospect wells were originally interpreted to be similar to that in Foinaven, this study demonstrates they are different in both their AVO behaviour and spectral characteristics.

KEYWORDS: AVO, West of Shetland, fluid-lithology discrimination, spectral decomposition, iso-frequency

\section{INTRODUCTION}

Since 1993 approximately 40 wells have been positioned on an amplitude or AVO anomaly located within the Paleocene west of Shetland, UK, but only nine encountered notable hydrocarbons, resulting in a drilling success rate of only $23 \%$ for this play. A large number of the failed wells were positioned on interpreted AVO or high amplitude features believed to be coinciding with the termination or up-dip limit/pinch-out edge of a sandstone interval (Loizou 2003, 2005). Moreover, the early work in a number of cases indicated that there was a high chance of hydrocarbons being present and that the anomaly conformed to a Class III (for the definition of AVO Classes, see Rutherford \& Williams 1989). In his post mortem analyses, the first author of this paper has suggested that the majority of failures relate to poor definition of traps that had been mapped on the basis of AVO artefacts and spurious amplitudes, and those wells that encountered hydrocarbons were positioned on robust structural closures or combination traps (Loizou 2005; Loizou et al. 2006). He further argued that the problems associated with the AVO analysis in the West of Shetlands region include: (1) many 3D seismic datasets were acquired with a $3 \mathrm{~km}$ cable length and hence the data in many cases were not ideal for robust AVO studies, and (2) considerable difficulties have been experienced in separating amplitudes associated with contrasting lithologies from those associated with fluids (hydrocarbons).

AVO analyses have proved to be a robust indicator of hydrocarbons in the Tertiary basin-floor fan plays offshore Angola and in other comparable plays worldwide. There is as yet no clear consensus as to why AVO analyses have often 
failed to deliver accurate predictions of hydrocarbons in the Paleocene strata of the West of Shetlands region.

One of the primary aims of this AVO analysis is to provide an improved understanding of AVO classifications and the way to differentiate fluid effects from lithology in the Paleocene strata West of Shetland. The locations of the four exploration wells used for the study are shown in Figure 1 (lithology and the main formations are summarised in the recent paper by Loizou et al. 2006). Several techniques have been used to obtain AVO signature, including conventional AVO attribute study, together with more recent techniques such as spectral analysis and a modelling-based approach. The 204/18-1 Assynt failure is of particular interest, comparing the AVO response computed for Assynt to that of 204/17-1 and the nearby Foinaven 204/24a-2 well. Less detailed analysis was performed for the Laggan 206/12 well. The AVO analysis of the four wells is based on intervals encountered within the Palaeocene Vaila Formation, particularly the T31 to T36 interval. For this study, there is a particular focus on the examination of the offset stack data and the AVO cross plot analysis.

For most of the second part of the paper there is an analysis and comparison of the spectral characteristics from the wells studied. Spectral decomposition is applied to the data from these wells and provides further evidence that there are also differences in the spectral characteristics between the wells. Spectral decomposition is a relatively new technique and its popularity has increased in geophysics since the pioneering work of Partyka et al. (1999) and Castagna et al. (2003). Recently, Chapman et al. (2005) have extended the application of spectral decomposition analysis to AVO studies in the framework of the Rutherford and Williams AVO analyses (Rutherford \& Williams 1989). For both Foinaven and Laggan, Class III AVO anomalies are consistent with theoretical predictions for frequency-dependent AVO behaviours. Results from the spectral analysis of the 204/18-1 and 204/17-1 wells show rather complicated behaviour in the iso-frequency sections that cannot be fully explained. Generally, the amplitude anomalies for both prospects were originally interpreted to be quite similar to that for Foinaven, but this study indicates they are different in both the AVO behaviour and their spectral characteristics. Nevertheless, the spectral characteristics for the Foinaven and Laggan wells are consistent with theoretical predictions, while the results from the other two prospect 
wells show different and rather complicated behaviours that cannot be fully explained.

\section{AVO PROCESSING AND ANALYSIS PROCEDURE}

The basic principle of the AVO technique has been described in many papers (Castagna et al. 1993, 1998). The following processing sequence and analysis procedures are used here to re-process the seismic data for AVO signatures:

- Pre-processing. Note that all seismic data were pre-processed prior to delivery for the AVO analyses and we assume that these have been properly performed (including mainly, but not restricted to, multiple attenuation, de-noising, geometrical spreading corrections, etc). The seismic data were processed to zero phases, i.e. the positive amplitudes on shaded wiggle traces correspond to increases in impedance for those events marked with arrows (see next section). However, we will see later that the data from four areas have variable quality, including existence of residual multiples, and residual moveouts (non-flat events), etc. These will also affect the AVO results.

- Pre-stack amplitude analysis. A visual inspection is made of the amplitudes of selected CDP gathers from each area at selected locations to compare the amplitude responses in and outside the anomalous reservoirs zones.

- Range or partial stack. In the standard AVO processing, it is common to perform a so-called offset stack (sometimes called the angle or partial stack, see Hendrickson 1999; Smith \& Gidlow 1987). The idea is that the NMO-corrected CDP data are divided into a range of offsets (or angles). Then the data can be stacked within these limited offset (angle) ranges. Most often, the data are divided into just near and far offsets before stacking. For this particular study, the seismic data are divided into three offset ranges, namely: near, middle and far offset ranges, and then a comparison is made of the amplitudes in each offset range with conventional full-offset stack amplitudes. In doing so, one can basically confirm the AVO type (as illustrated in Fig. 2).

- AVO attribute analysis. Standard AVO attributes, such as AVO intercept, gradient, curvature and the fluid factors are computed. The basic principle has been described in various papers (Castagna \& Smith 1994; Foster et al. 1997; 
Sams 1998; Pan et al. 2006). Figure 3 shows the Castagna et al.'s (1998) classification of AVO types. The class I, II and III curves show the Rutherford and Williams (1989) classification for gas sands. Note that this classification is based only on the normal-incidence reflection coefficient (intercept A). Class I sands are high impedance relative to the overlying shales and gives positive AVO intercept (A) and negative AVO gradient (B). Class II sands have low normal incidence reflectivity (small impedance contrast). Class III sands are lower impedance than the overlying shales, and exhibit increasing reflection magnitude with offset (negative AVO intercept, A, and negative AVO gradient, B). Class IV was introduced by Castagna et al. (1998) for the case where initially negative reflection coefficients become more positive with increasing offset (negative intercept, A, and positive gradient B). Phase reversals may be associated with Class I AVO in far offsets, and may occur for Class II in the near to middle offsets.

- Spectral decomposition. Recently, it has been shown that spectral characteristics can also be indicative of fluids (see Chapman et al. 2005; Odebeatu et al. 2006). For this study, comparisons of the spectral data from selected CDP gathers in and outside the anomalous reservoir zones were made. We observe that they typically display different characteristics. Spectral analyses were mainly applied to the Foinaven and Laggan data.

In addition, studies have been performed on the tuning effects. Tuning effects are caused when the seismic wavelength is comparable to, or greater than, the thickness of targets (Dong 1999; Liu \& Schmitt 2003).

\section{COMPARISON OF AVO ANALYSES FROM FOUR WELLS}

At least one or two 2D lines of seismic data are extracted from 3D surveys for use in the AVO analyses from the four wells. Well log data when available were utilised for the AVO attribute computations (i.e. Foinaven, Assynt, Fleet North), and for Laggan, we used a simplified model from well log data in the BGS/DTI core store archive.

The AVO results from wells 204/24a-2 and 206/1-2 are reviewed in more detail by Loizou et al. (2006). Moreover, the same paper discusses in terms of 
geology and structural setting as to why the 204/18-1 Assynt Prospect well failed to find hydrocarbons in contrast to the nearby Foinaven hydrocarbon province.

\section{Foinaven Oil Field (discovery well 204/24a-2)}

The location of Foinaven is unique in terms of hydrocarbon charge history west of Shetland, reservoir quality and trapping style, as most of the field is a combination of structural and stratigraphic trap (Cooper et al. 1999; Parr et al. 1999). Foinaven well 204/24a-2 provides an excellent example of a soft/negative acoustic response that increases with offset angle (Fig. 4). The well actually penetrated multiple reservoirs of Palaeocene T31 to T34 sandstones, each with separate hydrocarbon contacts. Cross-plot analysis over a $12 \mathrm{~ms}$ window (2108 to $2120 \mathrm{~ms}$ ) relating to the shallower T34 sands shows a discrete, Class III AVO trend (Fig. 5). The AVO cross-plot analysis (Fig. 6) for the slightly deeper interval between 2130 to $2160 \mathrm{~ms}$ shows an impressive and pronounced separation of sealing intra-formational shales, which exhibit a Class I to IV trend, whilst the underlying T32 oil sands show an apparent Class III AVO response.

\section{Laggan Gas Field (discovery well 206/1-2)}

The Laggan gas accumulation was discovered in 1986 by the well 206/1-2, which encountered gas pay in the Palaeocene, T35 Vaila Formation sandstones. The gas is contained in three separate sands totalling $62 \mathrm{~m}$, which are equivalent to $33 \mathrm{~ms}$ of two way travel time (TWT) (interval velocity of $3758 \mathrm{~m} / \mathrm{s}$ ) situated at a depth of $3815 \mathrm{~m}$ true vertical depth sub-sea (TVDSS). This interval is represented on 3D seismic data by only one event as a result of tuning. Examination of the CDP gathers at the 206/12 well location shows a definite increase in amplitude with offset (Fig. 7). A crossplot from a $20 \mathrm{~ms}$ interval extracted from the gas-bearing unit (interval) shows a distinct Class III AVO anomaly (Fig. 8).

\section{Assynt Prospect (well 204/18-1) and Fleet North (well 204/17-1)}

Well 204/18-1 was positioned in the Foinaven sub-basin on a high amplitude anomaly referred to as Assynt (Fig. 9), and was largely a geophysically-driven 
prospect. The amplitude anomaly was seen and interpreted by a number of major companies to be a direct fairway analogue to discoveries such as Foinaven. However, Loizou et al. (2006) have stated that in contrast to Foinaven, there is no true evidence of amplitude conformance with depth. They further conclude that the predominantly stratigraphic nature of the Assynt prospect relied heavily on the presence of a sealing mechanism. At the nearby Foinaven and Schiehallion Fields, the existence of a thick and dominantly mud-prone T35 low-stand wedge provides a ubiquitous top seal. The location of Assynt shows it to be down-slope of, or even within, the basin-ward equivalent of this package. An overlying Palaeocene T36 Shale/Tuff sequence would thus be required to provide the ultimate top seal to the Assynt prospect (see Loizou et al., 2006, for a detailed discussion about the structural geology of the Assynt prospect).

Examination of the near- and mid-offset stacks at the 204/18-1 well (375 to $2241 \mathrm{~m}$ ) around $2900 \mathrm{~ms}$ generally shows a strong high amplitude response (Figs. 10 $\&$ 11). However, on the far offsets (2241-3175 m) the amplitudes are much weaker (Fig. 12).

Figure 13 shows the full-offset section with high-amplitude zones marked, which were interpreted as anomalous 'bright spot' AVO. Figs. 10, 11 and 12 show the stacked sections from near, middle and far offset ranges. Anomalous high amplitudes can be seen in both near (Fig. 10) and middle (Fig. 11) offset ranges, but do not show up as strongly in the far offset range (Fig. 12). This would imply that the data do not show Class III bright spots, and instead reveal typical Class I or Class II AVO (amplitude decreases with increasing offset).

To further confirm that the high amplitude anomaly is not associated with Class III bright spot AVO, a selection of CDP gathers was examined after NMO correction. Fig. 14a shows a CDP gather 5401 from the left of the anomalous zone, and Figure 14c shows a CDP gather 5651 from the right of the anomalous zone. They can be compared with a typical CDP gather 5525, typical of the anomalous zone in Figure 14b. Interestingly, all three CDPs in Figure 14 show amplitudes dimming with offset, which conforms with the initial assessment that the high amplitude anomaly is not due to a Class III bright spot. Significantly, post-drill AVO analysis of the Assynt amplitude anomaly from well 204/18-1 shows a normal background trend (Fig. 15). 
A key question to consider is why there are high amplitudes only in some parts of the stacked section. Further detailed analysis of CDP gathers reveals an interesting observation. From Figure 14, one finds that although all the three CDPs display amplitude decreasing with offset, the rate of decrease is faster in the left (Fig. 14a) and right (Fig. 14c) gathers in contrast to the gather in the middle (anomalous) zone (Fig. 14b).

Observations can be made from manual extraction of the amplitudes along the two key horizons as shown in Figs. 16 and 17. For instance, for the left CDP (5401) and right CDP (5651), the amplitudes reach zero at offsets of approximately between 1.5 and $2 \mathrm{~km}$ (Fig. 16), whereas for the CDP from the anomalous zone (5535), the amplitudes begin to reach zero at offsets at least beyond $3 \mathrm{~km}$ (Fig. 17). Normally, after the amplitudes reach zero, a distinct polarity change is observed. Further inspection of the pre-stacked CDP gathers in Figure 14 shows that there are noticeable phase reversals in Figs. 14a and 14c (indicative of the possible Class II AVO), but no phase reversal is seen in Figure 14b. From this, a possible explanation of the Assynt anomaly can be made. The stacked sections on the left and right sides of the Assynt anomaly show dimming because of the cancellation of amplitudes (due to phase reversal), whereas in the middle section, the amplitudes are enhanced by stack as there is no phase reversal.

Another question would be what causes the difference in AVO signatures along the line? One possible explanation would be lateral variation in $V p / V s$ and lithology (porosity) changes. For Class I AVO (reflection from a low to high impedance boundary), increase in porosity (decreasing $V p$ in the lower layer) will shift the zero-crossing in amplitudes towards near offsets, and an increasing $V p / V s$ in reservoir layers will shift the zero-crossing in amplitudes toward larger offsets, as shown in Figure 18 (generally expect that an increase in the overburden shale $\mathrm{Vp} / \mathrm{Vs}$ ratio will shift the zero-crossing to near offsets). Therefore, one could infer that the Assynt high amplitude anomaly may be related to an increase in the $\mathrm{Vp} / \mathrm{Vs}$ ratio in this zone (possibly as a result of localized increase of porosity, which reduces the shear wave velocity proportionately more than the compressional wave velocity). Other factors such as shale anisotropy may also influence AVO (Wright 1987; Margesson \& Sondergeld 1999), but the discussion of the anisotropy effect is beyond the scope of this paper. 
It is noted that because the Assynt location is down-slope relative to Foinaven, and Foinaven shows classical bright spots associated with the Class III AVO, we would also expect Class III AVO if the Assynt prospect were similar to Foinaven. This is because Class I AVO would normally be expected to be associated with shallow targets where overburden shale would be less compacted and the sand porosity in both Assynt and Foinaven are similar, resulting in high impedance sands relative to overlying shale. The fact that we see Class I AVO in Assynt indicates the significant difference between Assynt and Foinaven and may effectively rule out the hydrocarbon prospect.

Well $204 / 17-1$ is located just $8.8 \mathrm{~km}$ to the southwest and marginally up-dip of the Assynt well 204/18-1, but was positioned on a smaller amplitude anomaly (Fig. 19). Post drilling analysis of 204/18-1 shows that overlying the Assynt anomaly unit is a non-sealing sequence comprising predominantly thick sandstone and siltstone lithologies (Loizou et al. 2006). Bearing this in mind, the 3D seismic data do not show evidence that the lithology overlying the amplitude anomaly at the 204/17-1 location would be any different from that penetrated by the 204/18-1 well. Therefore, of particular importance is the necessity for a sealing lithology above the 204/17-1 anomaly to create an effective trap.

Review of the CDP gathers for the 204/17-1 well (Fig. 19) shows that the data are heavily muted to approximately $2540 \mathrm{~m}$ in offset and that the positive amplitudes observed at approximately $2660 \mathrm{~ms}$ decrease with offset. Amplitude extraction over the high amplitude anomaly at the well location between 2660 to $2690 \mathrm{~ms}$ used for the AVO cross-plot shows the key characteristics of a Class I AVO anomaly. The results of the well confirm very similar lithologies immediately above the anomaly to those encountered at the 204/18-1 well (approximately 500 feet of sandstones overlying the anomalous zone). The pre-drill prognosis from the operator (Hinkley \& Lawson 2004) was that the 'high amplitudes' represented low impedances that were interpreted to be oil-filled siliciclastic sediments. The 204/17-1 Fleet North Prospect was interpreted as a direct hydrocarbon indicator, although only partial conformance between amplitude and structure was observed. Following a well post-mortem, failure was mainly attributed to the absence of top seal. The seismic anomaly was interpreted by Loizou et al. (2006) as due to an interface that is characterized mainly by an interbedded succession of sandstones, shales and volcaniclastic tuffs. 


\section{EFFECTS OF DISPERSION AND ATTENUATION ON AVO}

Velocity dispersion and attenuation of seismic waves can arise from either seismic scattering or intrinsic absorption due to the presence of fluids in porous media. The transition frequency related to the maximum dispersion and attenuation can occur within the seismic frequency band if there exists abnormally high reservoir attenuation. So far there is little consensus about the physical mechanism of attenuation, and different mechanisms may exist for dispersion and attenuation in the sonic and seismic frequency bands. For example, the following mechanisms have been proposed: fluid flow in cracked porous media (equant porosity model) described in Pointer et al. (2000) and Krzikalla et al. (2006); fluid flow between meso-scale regions (double porosity model) described by Pride et al. (2003); inclusion-based squirt flow model studied by Chapman et al. (2003); partial and patch saturation models (Carcione et al. 2003), and fracture in porous media (Lambert et al. 2006). Comprehensive literature reviews are given by King and Marsden (2002); King (2005); Chapman et al. (2006), and Batzle et al. (2006). However, although a range of possible mechanisms exist, many appeal to the movement of fluids relative to the rock matrix, allowing Dvorkin \& Mavko (2006) to assert that there is sufficient evidence in sedimentary rocks that attenuation and dispersion are related to fluids.

In recent papers, Chapman et al. $(2005,2006)$ have shown how to implement ideas from squirt-flow theory to model hydrocarbon-related dispersion and attenuation anomalies, which will be used in this paper to explain qualitatively the frequency-dependent observations. One of the conclusions is that P-wave reflection coefficients can become strongly frequency dependent. Synthetic modelling by Chapman et al. (2005) and field data examples by Odebeatu et al. (2006) are used to show that AVO characteristics at a plane interface bounded by two poro-elastic halfspaces can be highly influenced by frequency (dispersion and attenuation). A similar example was also given in a recent study by Hubert et al. (2005).

An example of the expected variation of velocity as a function of frequency is shown in Figure 20 using the poroelastic model developed by Chapman et al. (2003) with parameters listed in Table 1 (taken from Chapman et al. 2006). Figures 21 and 22 show the variations of P-wave reflection coefficients with saturation and frequency for typical Classes I and III AVO, respectively. For the Class I interface 
(Fig. 21), i.e. an interface with low to high impedance contrast, frequencies above the transition frequency will enhance the AVO effect due to the increase in impedance contrast across the interface. Therefore one would expect that for a Class I AVO, amplitudes would increase as frequency increases - the high frequency 'bright' spot. In contrast, for the Class III AVO, i.e. an interface with high to low impedance contrast, exactly the opposite is seen (Fig. 22), i.e. amplitudes would be expected to dim as frequency increases above the transition frequency - the low frequency 'bright' spot. The variation of AVO with frequency is also heavily dependent on the presence of saturated fluids as shown in Figs. 21 and 22.

Table 1. Numerical values used in the computations. The sand velocities assume water saturation. In all cases, the reference frequency is $10 \mathrm{~Hz}$, with the reference relaxation time $\tau_{0}=20 \mu \mathrm{s}$, and randomly distributed micro-crack density is $\varepsilon_{0}=0.1$. The oil bulk modulus is assumed to be $800 \mathrm{MPa}$, and the gas bulk modulus is taken as $400 \mathrm{MPa}$.

\begin{tabular}{|c|c|c|c|c|c|c|c|}
\hline & & $\begin{array}{c}\text { Vp } \\
(\mathrm{km} / \mathrm{s})\end{array}$ & $\begin{array}{c}\text { Vs } \\
(\mathrm{km} / \mathrm{s})\end{array}$ & $\begin{array}{c}\rho \text { water-sat } \\
(\mathrm{g} / \mathrm{cc})\end{array}$ & $\begin{array}{c}\rho \text { gas-sat } \\
(\mathrm{g} / \mathrm{cc})\end{array}$ & $\begin{array}{c}\rho \text { oil-sat } \\
(\mathrm{g} / \mathrm{cc})\end{array}$ & $\phi$ \\
\hline Model 1 & Shale & 2.249 & 0.731 & 2.139 & - & - & - \\
\cline { 2 - 8 } & Sand & 2.771 & 1.499 & 2.08 & 2.02 & - & $30 \%$ \\
\hline Model 2 & Shale & 3.166 & 1.689 & 2.32 & - & - & \\
\cline { 2 - 8 } & Sand & 2.95 & 1.8 & 2.3 & - & 2.28 & $15 \%$ \\
\hline
\end{tabular}

\section{APPLICATION OF SPECTRAL DECOMPOSITIONS AS AN AID TO AVO ANALYSIS}

The modern instantaneous spectral analysis technique or spectral decomposition is an ideal tool to detect the effect of frequency-dependent AVO. There are several techniques that can be used, such as short-window Fourier transform, discrete wavelet transform and Stockwell or S-transform. To perform the spectral decomposition and spectral analysis, we used the discrete wavelet transform with a Morlet wavelet (Chakraborty \& Okaya 1995). Our analysis follows the procedure detailed in the recent paper by Chapman et al. (2006). Note that we have performed extensive modelling studies on the effects of tuning on the spectral characteristics, and these 
studies have been published in a series of companion papers by Odebeatu et al. (2006), Chapman et al. (2006) and Zhang et al. (2007). The main conclusion is that the thin-layer tuning effect can be significant and is dependent on both offset as well as the ratio of the layer thickness over wavelength. However, dispersion/attenuation will still modify the spectral characteristics caused by tuning.and the tuning effect alone cannot cause the Class I high-frequency brightening and the Class III brightening as described above. Distinguishing or separating the two effects are current research topics. While it is likely that our observed spectral variations are due to the combined effects of both tuning and dispersion/attenuation of seismic waves in porous sands, the modelling studies by Odebeatu et al. (2006) and Chapman et al. (2006), and the analysis of physical laboratory data by Zhang et al. (2007), suggest that dispersion/attenuation characteristics can be significant and observable in seismic data.

\section{Foinaven well 204/24a-2}

As shown in the previous section, the Foinaven amplitude anomaly is associated with a Class III AVO. Figure 23 shows the iso-frequency sections of stacked data for four different frequencies ranging from 15 to $45 \mathrm{~Hz}$. Note that the maximum amplitudes in each iso-frequency section have been normalised to a constant (or reference) value so that relative amplitudes can be compared across different iso-frequency sections (the normalization is also applied to other data below). The area marked on Figure 23 shows the Foinaven amplitude anomaly. One can see a systematic decrease in amplitudes as frequency increases, and this variation is qualitatively consistent with the theoretical prediction shown in Figure 22 for oil-saturated reservoirs with the assumed crack distribution and relaxation time constant in Model 2.

\section{Laggan well 206/1-2}

The Laggan gas discovery well 206/1-2 also exhibits the characteristics associated with bright spot Class III AVO. A series of iso-frequency sections is shown in Figure 24. Again, there is a systematic decrease of amplitudes as frequency increases in the marked area, qualitatively consistent with the theoretical prediction for Class III AVO shown in Figure 22. Note that the corresponding gas-curves in Figure 22 are not 
shown, but it is expected that the effect will be stronger for gas saturation than for brine or oil saturation. Odebeatu et al. (2006) show that for thin reservoirs, the effect of tuning can also cause changes in frequency-dependent reflection amplitudes. As discussed earlier for the Laggan well, the tuning is a result of the relatively thin net sand thickness of $62 \mathrm{~m}$ made up of three separate sands equivalent to $33 \mathrm{~ms}$ of TWT.

\section{Assynt Prospect well 204/18-1}

As described earlier, the AVO analysis for the Assynt amplitude anomaly showed this to be a Class I AVO, rather than the Class III that was originally interpreted. Spectral decomposition was applied to the data to obtain iso-frequency sections between 10 $\mathrm{Hz}$ and $40 \mathrm{~Hz}$, and this reveals that the Assynt amplitude anomaly is only seen in the very low frequency ranges. Figure 25 shows a comparison of the iso-frequency sections for the frequencies ranging between 10 and $25 \mathrm{~Hz}$. Intriguingly, we see that the amplitudes in the marked area change markedly from an increase with frequency between $10 \mathrm{~Hz}$ and $15 \mathrm{~Hz}$, to a decrease with frequency between $15 \mathrm{~Hz}$ to $20 \mathrm{~Hz}$. This suggests that the Assynt anomaly is indeed concentrated on the very low frequency range over a very narrow frequency band. The increase of amplitudes with frequency is consistent with the prediction shown in Figure 21 for Class I AVO, but the sudden decrease thereafter cannot be fully explained. This may be due to combined effects of thin-layer tuning and fluid-related attenuation/dispersion (discussed at the beginning of this section).

\section{DISCUSSION}

About 40 wells were positioned on an amplitude or AVO anomaly within the Palaeocene west of Shetland since 1993. Of these, nine encountered notable hydrocarbons. Following post-mortem studies, the majority of the wells that failed to find hydrocarbons could be shown to represent poorly-understood amplitude anomalies, AVO artifacts and spurious DHI's. While a large number of the failed wells were positioned on AVO or high amplitude features interpreted to coincide with the termination or up dip limit/pinch-out edge of a sandstone interval (Loizou 2005; Loizou et al. 2006), it can be argued that the cause of the AVO or high amplitude features for these wells was poorly understood. 
The AVO technique can in certain cases add reliable constraints to quantitative reservoir characterization if it is correctly applied. Reliable AVO analysis would require an angle offset of about 35 degrees, and for an offset of up to $3 \mathrm{~km}$, this gives a sub-sea depth of approximately $2.1 \mathrm{~km}$ if we assume a straight ray path (this is reasonable considering the smooth variation of acoustic velocity). This is not ideal for robust AVO studies west of Shetland, where at least $75 \%$ of the drilled AVO anomalies were at depths greater than $2.1 \mathrm{~km}$ sub-sea. For increased accuracy and confidence in AVO analysis, there is a need to acquire seismic data with offsets longer than $5 \mathrm{~km}$ (corresponding to a sub-sea depth of about $3.5 \mathrm{~km}$, assuming an angle offset of 35 degrees). Despite the pitfalls, the use of AVO/DHI has been fairly widespread west of Shetland since the early 1990s. The optimal setting for the technique in the area is for gas detection in shallow, porous, poorly-consolidated clastic rocks of Eocene and late Paleocene age.

In order to carry out the AVO analysis, a conventional stack technique was used (full offset stack) with all the data NMO-corrected. Stack data of near, middle and far offsets were used to see the relative amplitude variations in each offset range. Selected CDP gathers for areas of interest ('anomalous' high amplitude zones) and outside the 'anomalous' zone were compared for each well to identify the lateral variations in AVO Classes. For Assynt, Class I AVO can typically be seen (with phase reversal shown on the far offsets). Foinaven data show typical 'bright' spot AVO (Class III), and Laggan is also primarily Class III AVO. Amplitudes and AVO types are shown to vary laterally, with sometimes distinctive differences between the 'anomalous' zones and data from either side. The lateral variation of AVO along seismic lines reflects a change either in fluid saturation or lithology characterized by the $V p / V s$ ratio.

Detailed analyses of spectral characteristics, including modelling with a newly developed rock physics model (Chapman et al. 2005, 2006), have revealed that Classes I and III show different responses to fluid saturation at low and high frequencies (for an example of spectral decomposition for Class I AVO, see Chapman et al. 2005, 2006). In particular, it is suggested that the changes in AVO signatures for Foinaven and Laggan are more likely related to the fluid saturation, while for Assynt, it may be related to changes in the $V p / V s$ ratio. Spectral analyses also reveal the strong effects caused by tuning (when wavelength is comparable to, or greater 
than, the layer thickness) as shown by Partyka et al. (1999) and recently demonstrated by Chapman et al. (2006). Whilst explorationists normally appreciate the presence of higher porosity sands, our modelling suggests that seismic anomalies generated by normal porosity sandstone containing hydrocarbons are indistinguishable from anomalously high porosity sandstone that is brine-filled in the Assynt prospect.

The study has focused on the evaluation of four wells with associated seismic datasets all of which have amplitude-related anomalies. Not surprisingly, all four wells have different characteristics in terms of AVO signature. Table 2 summarizes the main characteristics for the four wells studied.

\begin{tabular}{|c|c|c|c|c|}
\hline \multicolumn{5}{|c|}{ Table 2. Summary of AVO signatures } \\
\hline & Assynt & Fleet North & Foinaven & Laggan \\
\hline Fluid phase & Brine (?) & Unknown & $\begin{array}{c}\text { Oil } \\
\text { (near bubble point) }\end{array}$ & Gas \\
\hline AVO Class & I (II) & I (IV?) & III & III (and I) \\
\hline Phase reversal & Yes & No & N/A & N/A \\
\hline AVO Intercept & Positive & Positive & Negative & Negative \\
\hline AVO gradient & Negative & Negative & Negative & Negative \\
\hline
\end{tabular}

Finally, it is noted that data quality will also affect the AVO results. The four datasets that we have analyzed in this paper have variable data quality. Foinaven data as shown in Figure 4 have very high quality and the primary reflections can be clearly identified. Laggan data shown in Figure 8 have slightly poorer quality where residual multiples exist. The Assynt (Fig. 14) and Fleet North (Fig. 19) have very poor quality with residual moveouts (i.e. non-flat events). Since the data were provided to us after AVO pre-processing, we have not tried to enhance their quality further and have focused simply on the AVO analyses.

Of course, we are not arguing that hydrocarbons are uniquely associated with Class III AVO. However, we do want to emphasise that appropriate applications of AVO techniques are required. Moreover, the main message here is that by using suitable seismic data AVO is not an Achilles Heel but a valuable tool for de-risking prospects west of Shetland if it is applied appropriately. 


\section{CONCLUSIONS}

In summary, both the 204/17-1 and 204/18-1 wells failed to find hydrocarbons, where the early work indicated a strong classic Class III AVO anomaly. However, these studies demonstrate that both the amplitude anomalies conform to Class I AVO. For the hydrocarbon-bearing reservoirs encountered in 204/24a-2 and 206/1-2, both wells confirmed the presence of what was originally anticipated as a Class III AVO anomaly.

The spectral decomposition results presented in this paper reveal that there are also differences in the spectral characteristics between the four wells. Whilst Foinaven and Laggan conform to the theoretical predictions, the results from the Assynt Prospect show rather complicated behaviour in iso-frequency sections that cannot be fully explained. One particular highlight from the analysis was that, although the Assynt amplitude anomaly was originally interpreted as analogous to Foinaven, this study firmly indicates it is different in both its AVO behaviour and spectral characteristics.

Although the analysis has focused on just four wells, it shows that the appropriate use of AVO analysis forms a valuable tool for exploration. The main lesson that we have learned is that it is paramount, before any AVO analysis is performed, to understand the quality and suitability of the seismic data for such analysis.

ACKNOWLEDGEMENTS: The authors would like to thank our colleagues Don Cameron, Bob Gatliff and Xiang-Yang Li of the British Geological Survey (BGS) for their support, and in particular Jen Brzozowska of the Department of Trade and Industry (DTI) and Don Cameron (BGS) for detailed comments. We are grateful to those companies who supplied the data and to Mark Kassyk of the DTI/BGS Core Store in Edinburgh for his help in providing information that was needed for this work, and Jinghua Zhang (BGS) for her help with data processing. The constructive comments from the Co-Editor and two anonymous reviewers have greatly improved the readability of this paper and we thank them for their excellent work. This work was entirely done while one of the authors (Enru Liu) was employed by the BGS and 
the work was supported by the Department of Trade and Industry (DTI). This paper is published with the approval of the DTI and the Executive Director of BGS (NERC). The views expressed in this paper are the opinions of the authors only and are not necessarily those of the DTI or BGS (NERC).

\section{REFERENCES}

Batzle, M.L., Han, D.H. \& Hofmann, R. 2006. Fluid mobility and frequencydependent seismic velocity - direct measurements. Geophysics, 71, N1-N10.

Carcione, J., Helle, H.B. \& Pham, N.H. 2003. White's model for wave propagation in partially saturated rocks: Comparison with poroelastic numerical experiments, Geophysics, 68, 1389-1398.

Castagna, J.P., Batzle, M.L. \& Kan, T.K. 1993. Rock physics - the link between rock properties and AVO response. in Offset-Dependent Reflectivity - Theory and Practice of AVO Analysis, J.P. Castagna \& M. Backus, eds., Society of Exploration Geophysicists, Tulsa, Oklahoma.

Castagna, J.P. \& Smith, S.W. 1994. Comparison of AVO indicators: A modelling study. Geophysics, 59, 1849-1855.

Castagna, J.P., Sun, S. \& Siegfried, R.W. 2003. Instantaneous spectral analysis: detection of low frequency shadows associated with hydrocarbons. The Leading Edge, 22, 127-129.

Castagna, J.P., Swan, H.W. \& Foster, D.J. 1998. Framework for AVO gradient and intercept interpretation. Geophysics, 63, 948-956.

Chapman, M., Maultzsch, S., Liu, E. \& Li, X.Y. 2003. The effect of fluid saturation in an anisotropic, multi-scale equant porosity model. Journal of Applied Geophysics, 54, 191-202.

Chapman, M., Liu, E. \& Li, X.Y. 2005. The effects of abnormally high attenuation on AVO signatures. The Leading Edge, 24 (11), 1120-1125.

Chapman, M., Liu, E. \& Li, X.Y., 2006. The influence of fluid-sensitive dispersion and attenuation on AVO analysis. Geophysical Journal International, 167, 89105.

Chakraborty, A. \& Okaya, D., 1995. Frequency-time decomposition of seismic data using wavelet based methods. Geophysics, 60, 1906-1916. 
Cooper, M.M., Evans, A.C., Lynch, D.J., Neville, G. \& Newley, T. 1999. The Foinaven Field: managing reservoir development uncertainty prior to start-up. In Fleet, A.J. \& Boldy, S.A.R. (eds), Petroleum Geology of Northwest Europe: Proceedings of the $5^{\text {th }}$ Conference, Geological Society Publishing House, London, 675-682.

Dong, W. 1999. AVO detectability against tuning and stretching artefacts. Geophysics, 64, 494-503.

Dvorkin, J.P. \& Mavko, G. 2006. Modelling attenuation in reservoir and nonreservoir rock, The Leading Edge, 25, 194-197.

Foster, D.J., Keys, R.G. \& Reilly, A. 1997. Another perspective on AVO crossplotting. The Leading Edge, 16, 1233-1237.

Hendrickson, J.S. 1999. Stacked. Geophysical Prospecting, 47, 663-705.

Hinkley, R. \& Lawson, C. 2004. Exploring for stratigraphic amplitude traps in the Judd Basin, Block 204/17 Case study. Paper presented at the PETEX Meeting in London.

Hubert, L., Strecker, U., Dvorkin, J. \& Frestervoll, K. 2005. Seismic attenuation and hybrid attributes to reduce exploration risk - North Sea case study. Expanded Abstract, $75^{\text {th }}$ Ann. Internat. Mtg., SEG Expanded Abstracts, 436-439.

King, M.S. 2005. Rock-physics developments in seismic exploration: A personal 50year perspective. Geophysics, 70, 3ND-8ND.

King, M.S. \& Marsden, J.R. 2002. Velocity dispersion between ultrasonic and seismic frequencies in brine-saturated reservoir sandstones, Geophysics, 67, 254-258

Krzikalla, F., Müller, T.M., Hardy, B. \& Gurevich, B. 2006. Seismic wave attenuation and dispersion in patchy-saturated rocks - numerical experiments: Extended abstract E038 presented at the 68th EAGE Technical Conference and Exhibition, Vienna.

Lambert, G., Gurevich, B. \& Brajanovski, M. 2006. Attenuation and dispersion of Pwaves in porous rocks with planar fractures: Comparison of theory and numerical simulations. Geophysics, 71, N41-N45.

Liu, Y. \& Schmitt, D.R. 2003. Amplitude and AVO responses of a single thin bed. Geophysics, 68, 1161-1168. 
Loizou, N. 2003. Post-well analysis of exploration drilling on UK Atlantic Margin provides clues to success. First Break, 21 (4), 45-49.

Loizou, N. 2005. West of Shetland exploration unravelled - an indication of what the future may hold. First Break, 23 (10), 53-59.

Loizou, N., Andrews, I.J, Stoker, S.J. \& Cameron, D. 2006. West of Shetland revisited - the search for stratigraphic traps. In: Allen, M., Geoffrey, G., Morgan, R. \& Walker, I (eds). The Deliberate Search for the Stratigraphic Trap: Where Are We Now? Geological Society, London, Special Publication. 254, 225-245.

Margesson, R.W. \& Sondergeld, C.H. 1999. Anisotropy and amplitude versus offset: a case history from the West of Shetland. In: Fleet, A.J. \& Boldy, S.A.R. (eds) Petroleum Geology of Northeast Europe: Proceedings of the $5^{\text {th }}$ Conference. Geological Society, London, 634-643.

Odebeatu, E., Zhang, J., Chapman, M., Liu, E. \& Li, X.Y. 2006. Application of spectral decomposition to detection of dispersion anomalies associated with gas saturation. The Leading Edge, 25 (2), 205-210.

Pan, D.M., Liu, E. \& Yue, J.H. 2006. Comparison of the accuracies of elastic impedance. Journal of Seismic Exploration, 14 (4), 303-317.

Parr, R.S., Cowper, D. \& Mitchener, B.C. 1999. The search for mountains of oil: $\mathrm{BP} /$ Shell exploration activity in the Atlantic Margin, West of Shetland. SPE $56897(5 \mathrm{pp})$.

Partyka, G.J., Gridleyu, J. \& Lopez, J. 1999. Interpretational application of spectral decomposition in reservoir characterization. The Leading Edge, 18, 353-360.

Pride, S.R., Berryman, J.G. \& Harris, J.M. 2004. Seismic attenuation due to waveinduced flow. J. geophys. Res., 109 (B1), Article No. B01201.

Pointer, T., Liu, E. \& Hudson, J.A. 2000. Seismic wave propagation in cracked porous media. Geophys. J. Int., 142, 199-231.

Rutherford, S. R. \& Williams, R. H. 1989. Amplitude-versus-offset variations in gas sands. Geophysics, 54, 680-688.

Sams, M. 1998. Yet another perspective on AVO cross plotting. The Leading Edge, 17, 911-917.

Smith, G.C. \& Gidlow, P.M. 1987. Weighted stacking for rock property estimation and detection of gas. Geophys. Prosp., 35, 993-1014. 
Wright, J. 1987. The effects of transverse isotropy on reflection amplitude versus offset. Geophysics, 52, 564-567.

Zhang, J., Chapman, M., Liu, E., Li, X.Y., Wang, S. and Liu, Z., 2007. Fluid detection by spectral decomposition: lessons from numerical, physical modelling and field studies. Expanded Abstracts, $69^{\text {th }}$ EAGE Meeting, June 2007, London, P100. 


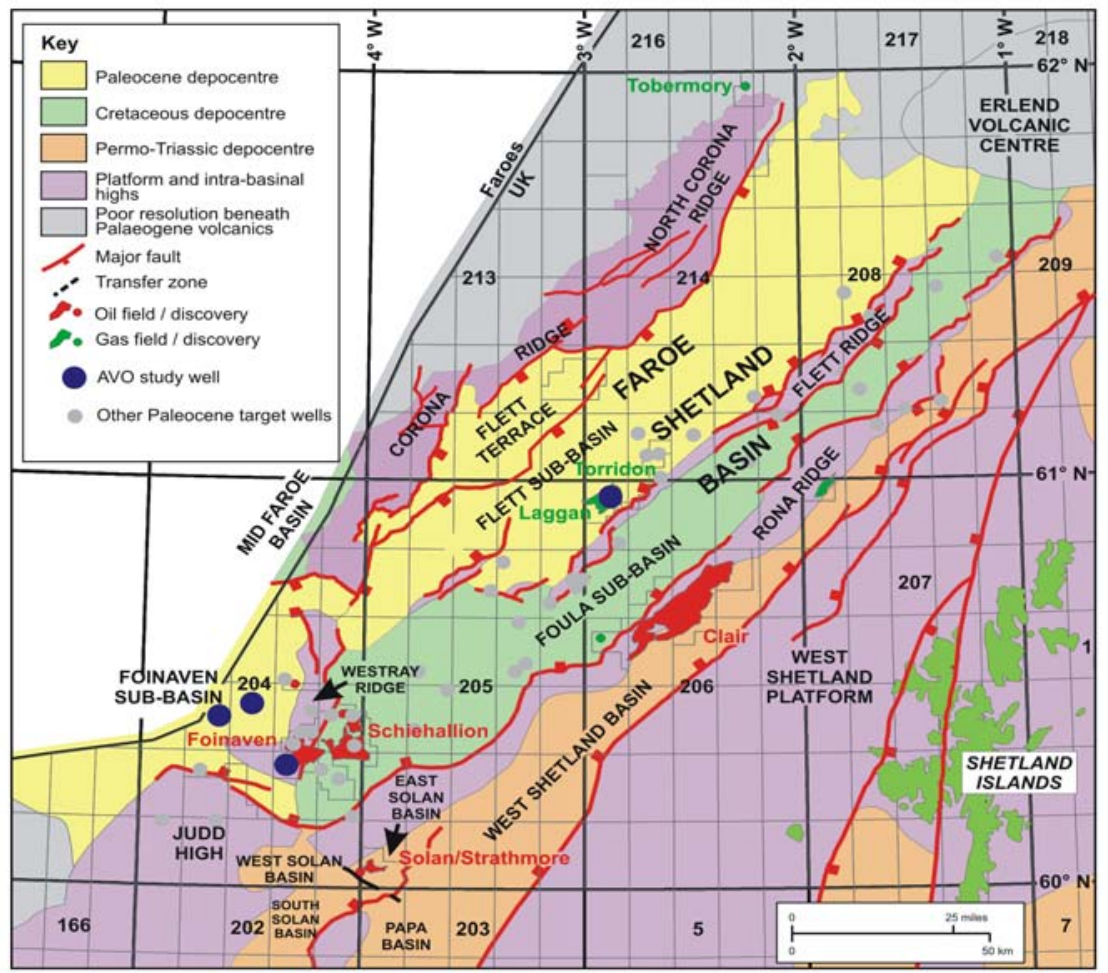

Fig. 1. Structural elements in the study area west of Shetland with locations of the four wells used in AVO analysis marked with blue dots: 206/1-2 (Laggan); 204/24a-2 (Foinaven); 204/18-1 (Assynt prospect) and 204/17-1 (Fleet North prospect).

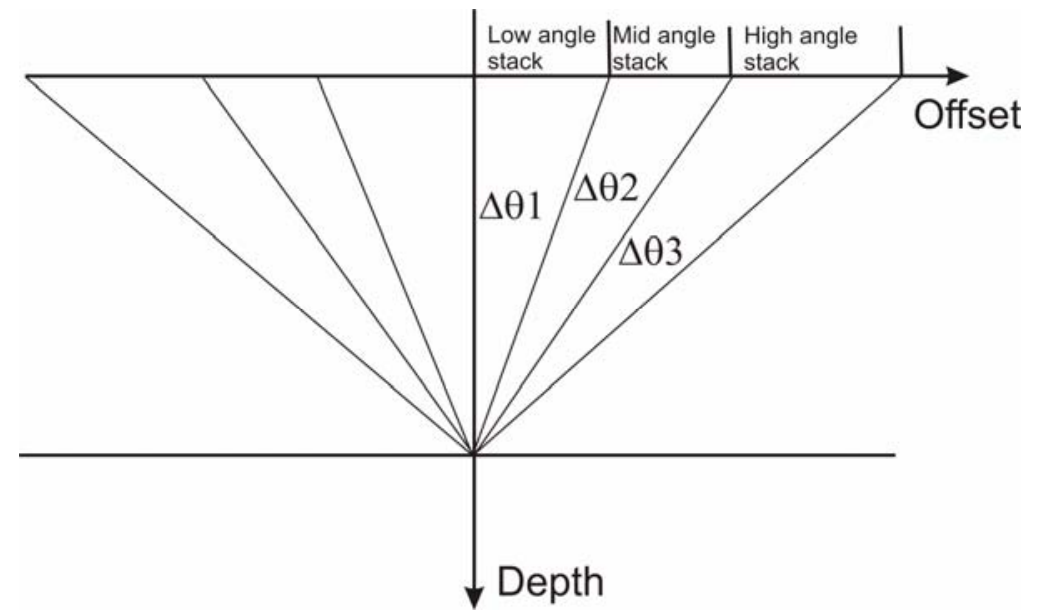

Fig. 2. Schematic diagram showing the angle (offset) stack. The pre-stack CDP data are divided into a range of offsets (or angles) and then stacked within the limited offsets. 


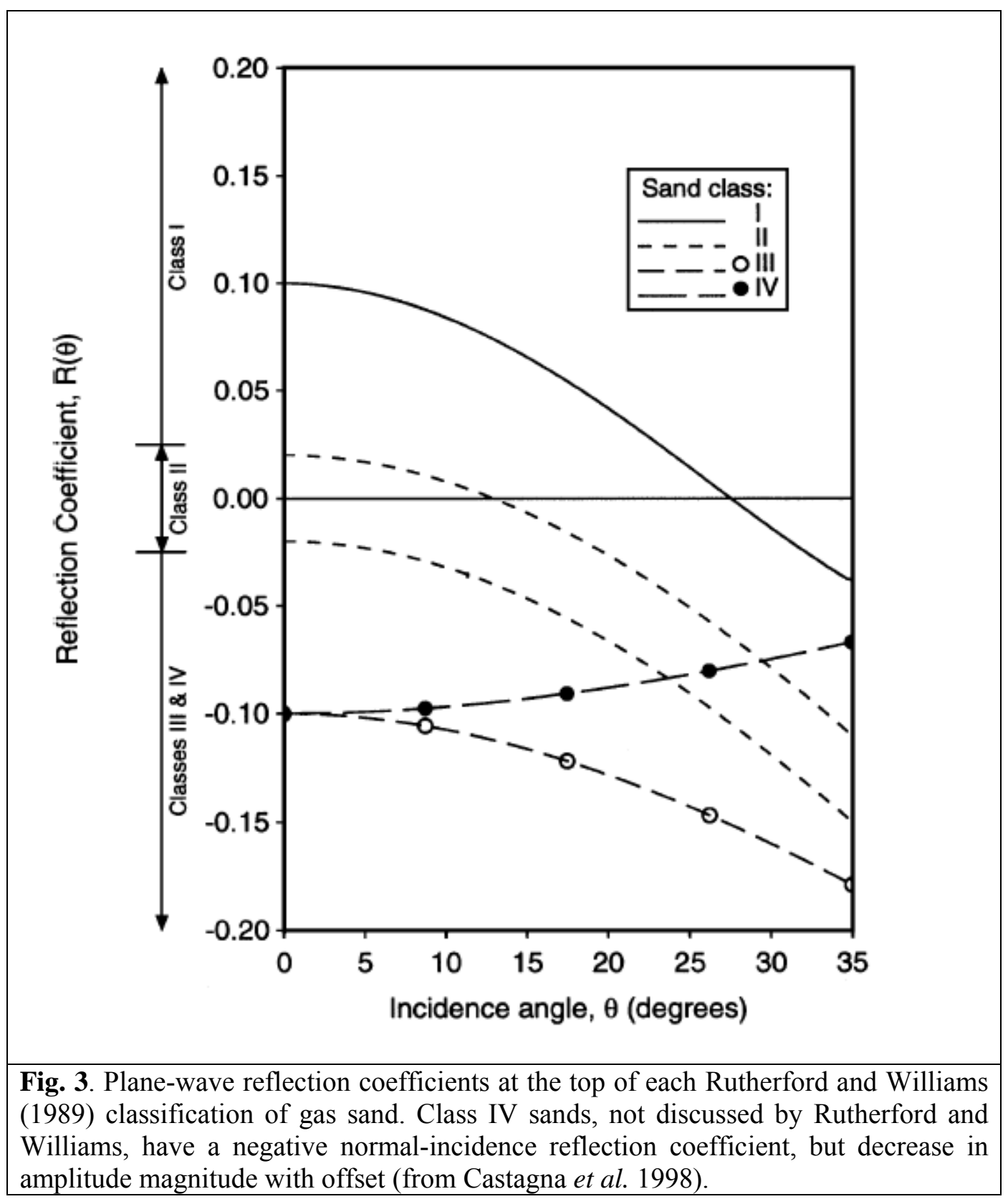




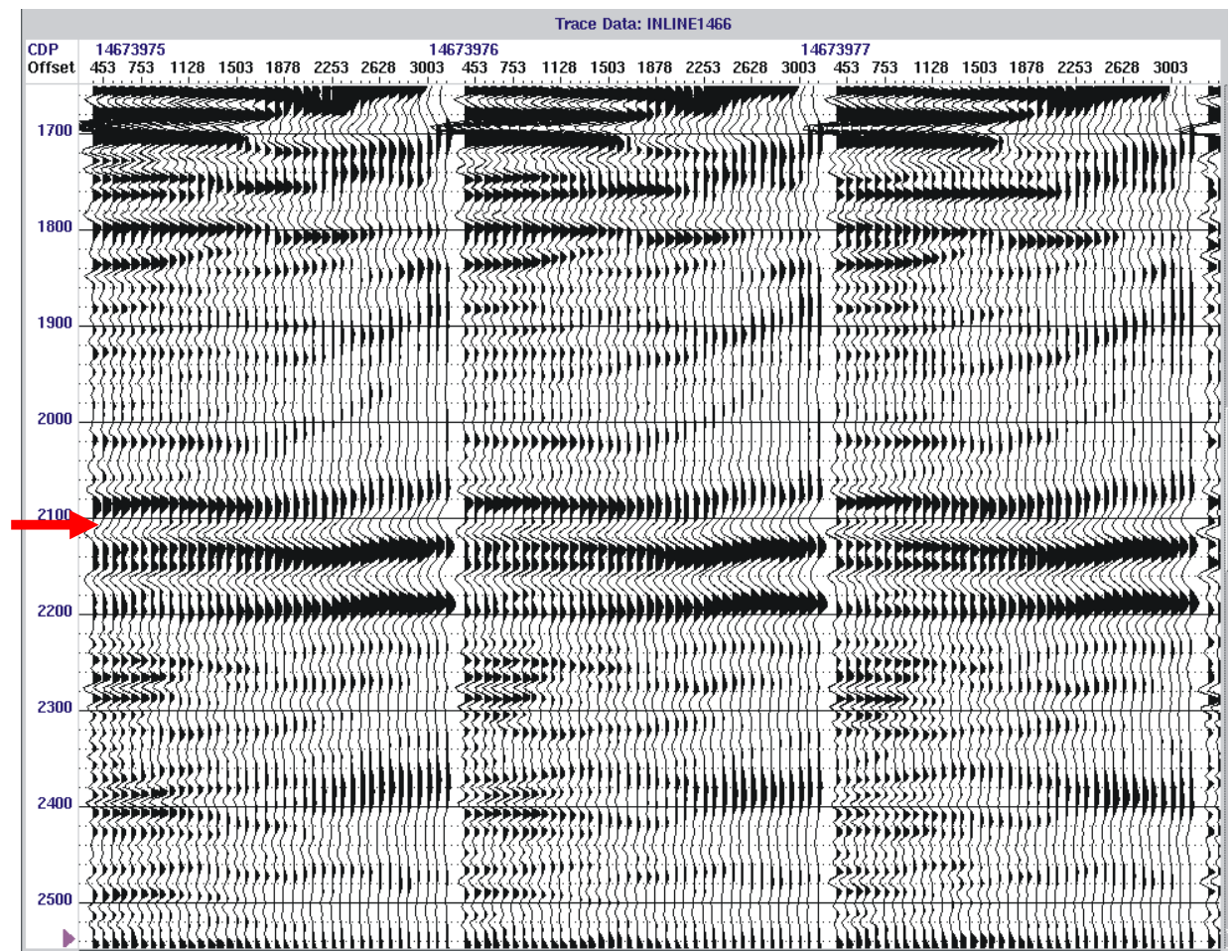

Fig. 4. CDP gathers for well 204/24a-2 showing amplitude increases with offset (the target is marked by an arrow).

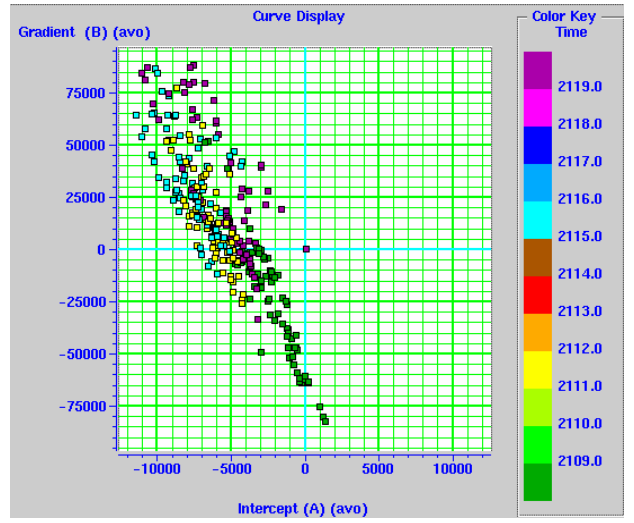

Fig. 5. Well 204/24a-2 shows a Class III AVO mainly due to a thin gas cap within Palaeocene T34 sandstones.

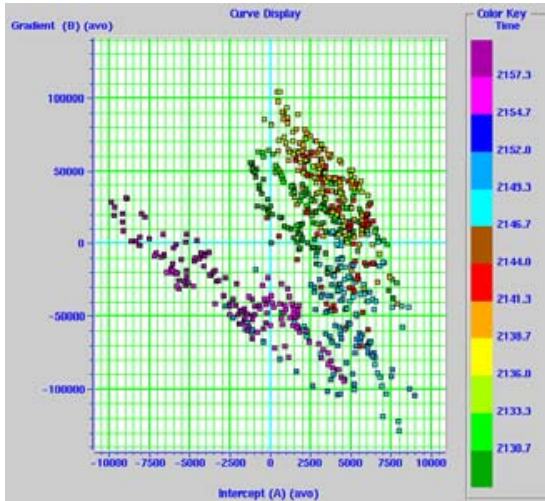

Fig. 6. Well 204/24a-2 shows the separation of T33 shales (Class I to IV AVO) with deeper T32 hydrocarbon bearing sandstones (Class III AVO). 


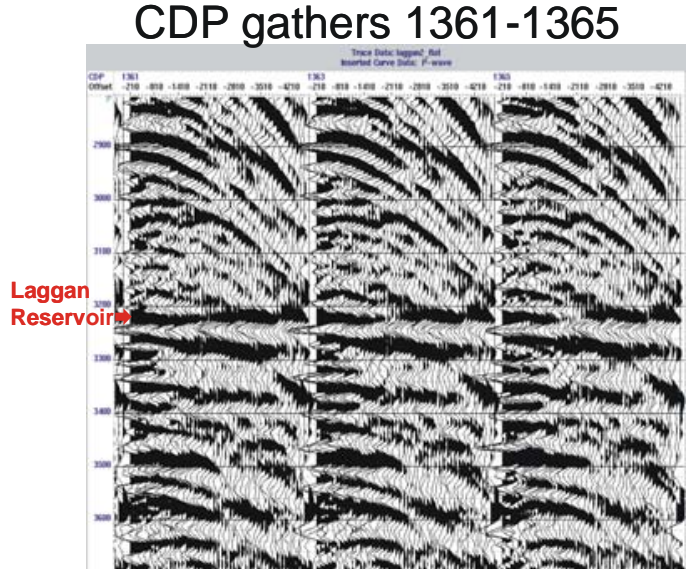

Increase of amplitude with offset

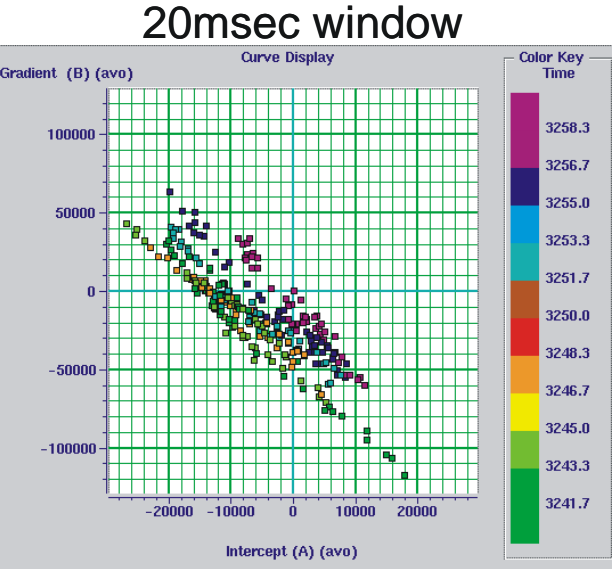

Class III AVO anomaly

Fig. 7. CDP gathers for well 206/1-2 Fig. 8. Well 206/1-2 shows primarily a showing amplitude increases with offset. Class III AVO anomaly.
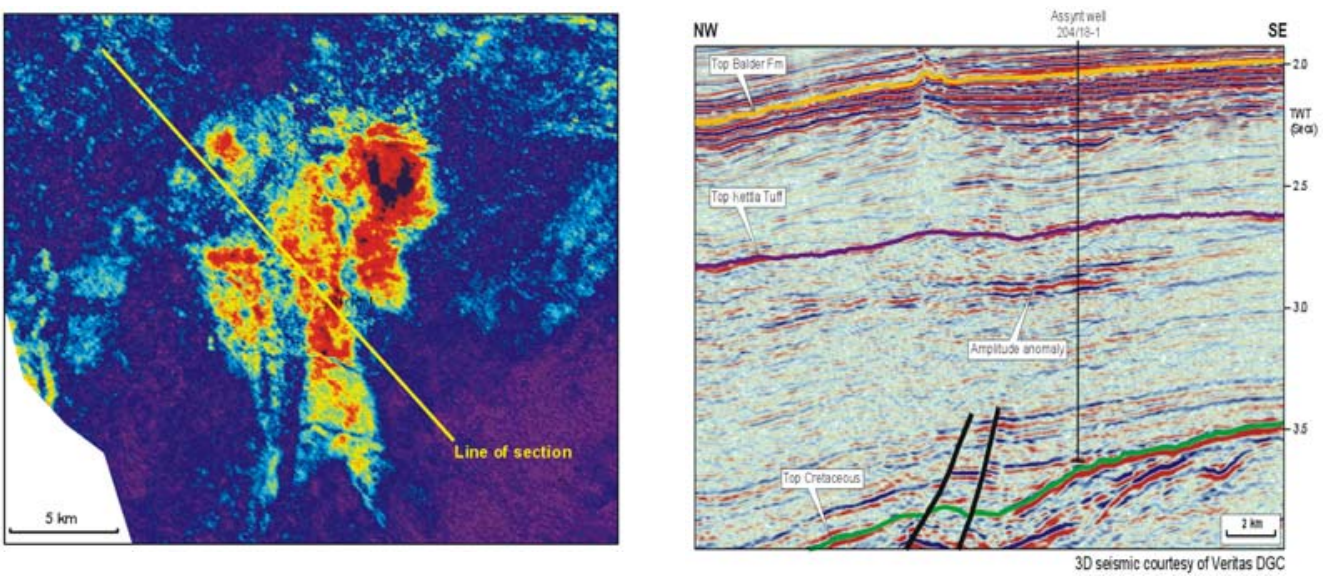

Fig. 9. Well 204/18-1 (Assynt Prospect) positioned on a high amplitude anomaly. 


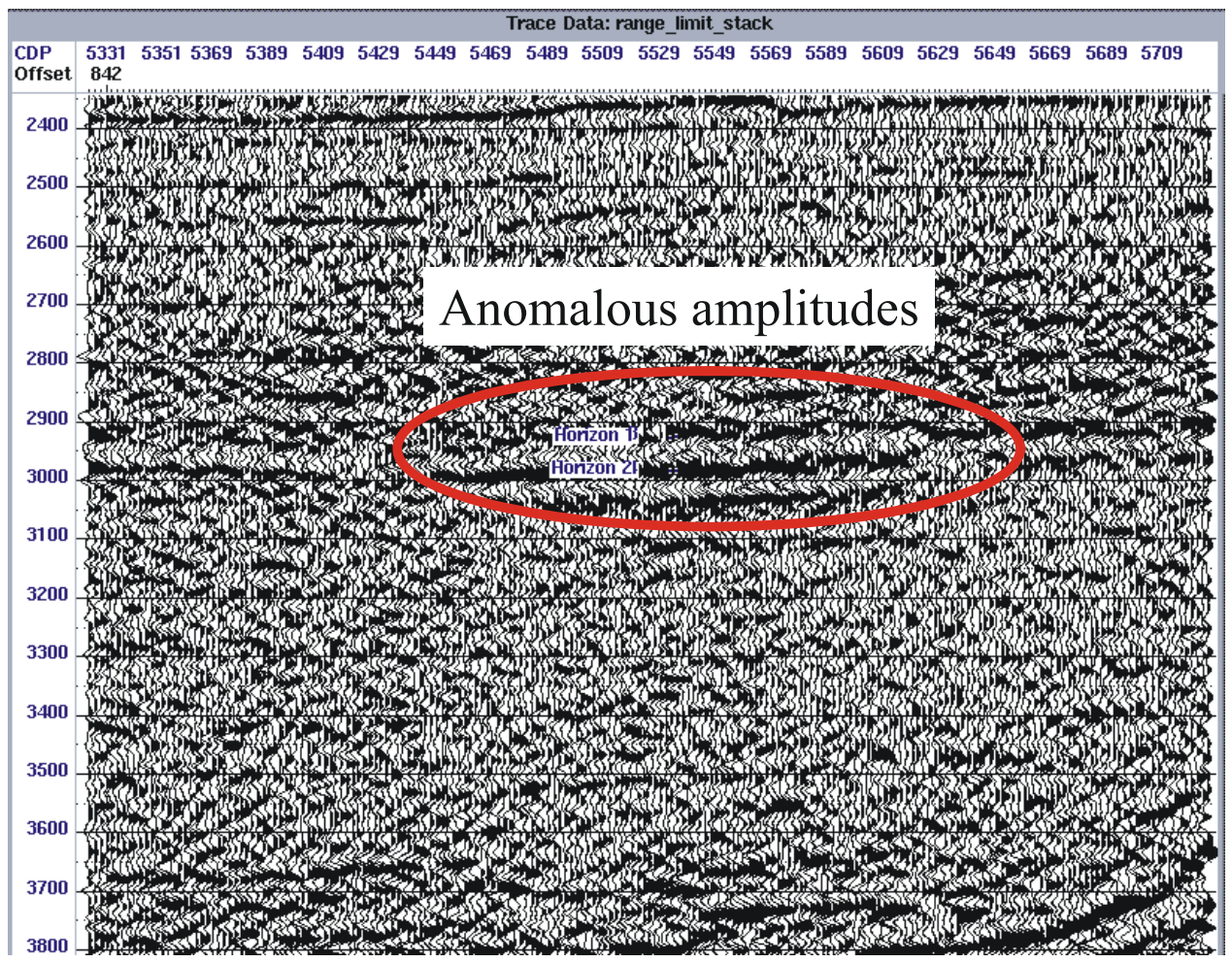

Fig. 10. Near offset stack (offset ranges 375-1308 m).

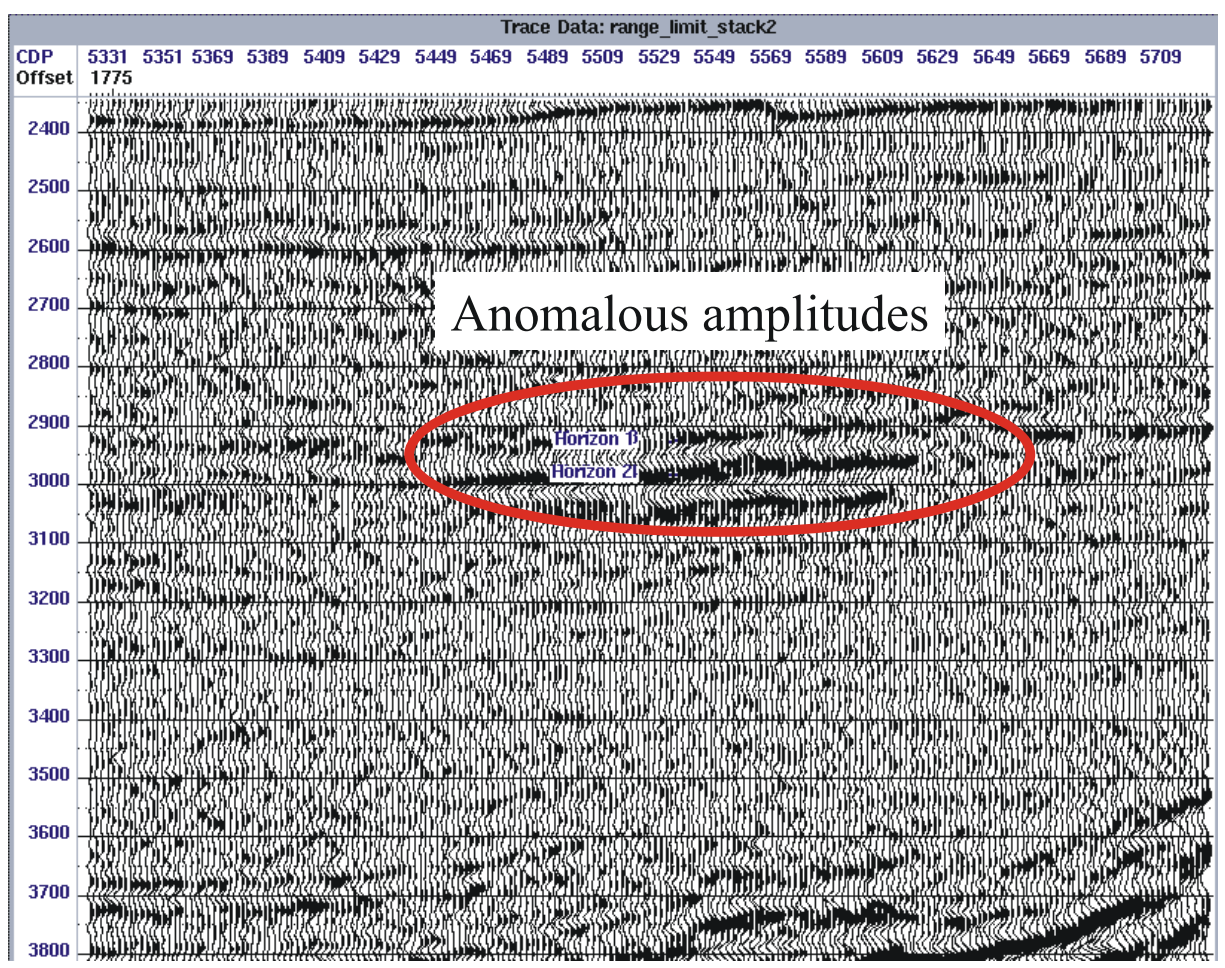

Fig. 11. Middle offset stack (offset ranges 1308-2241 m). 


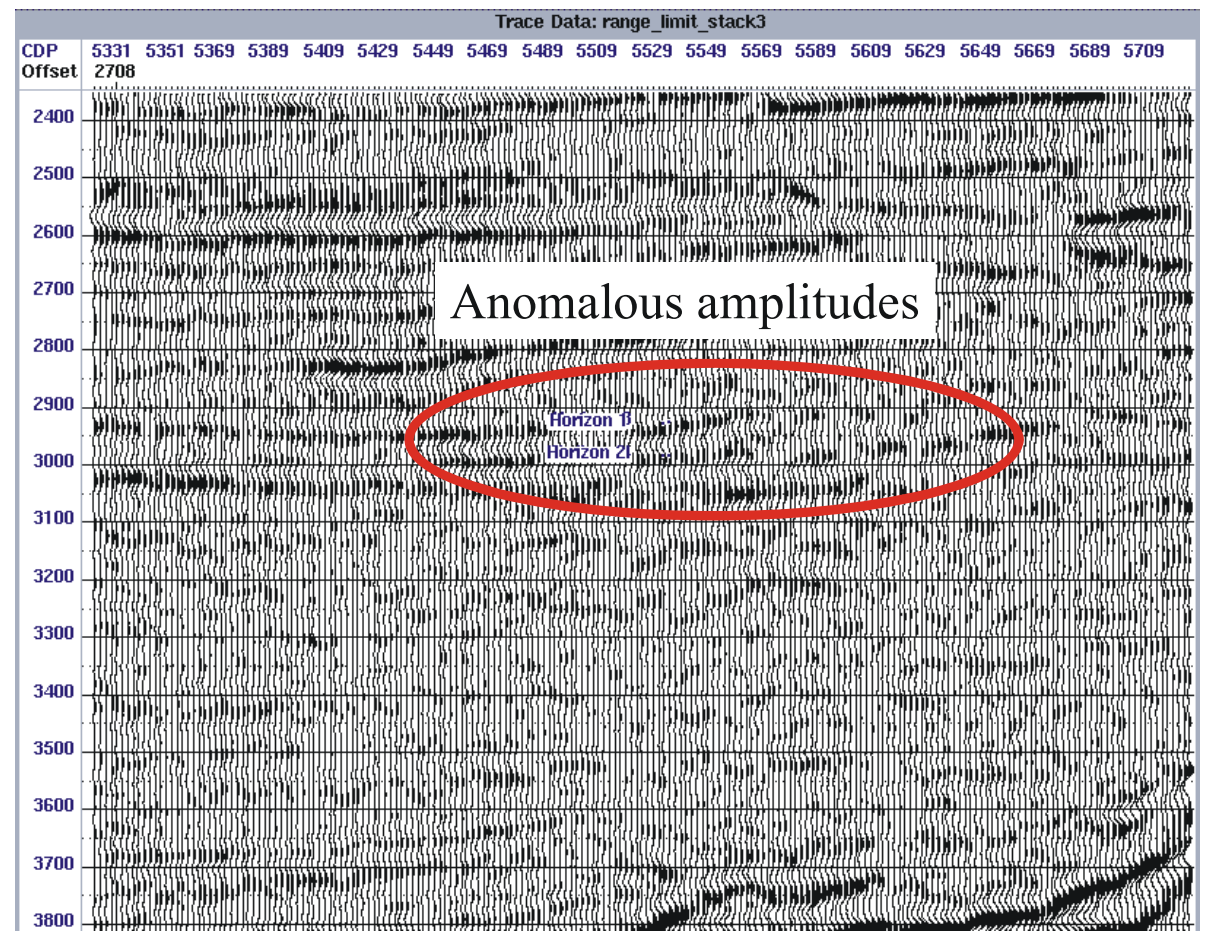

Fig. 12. Far offset stack (offset ranges 2241-3371 m).

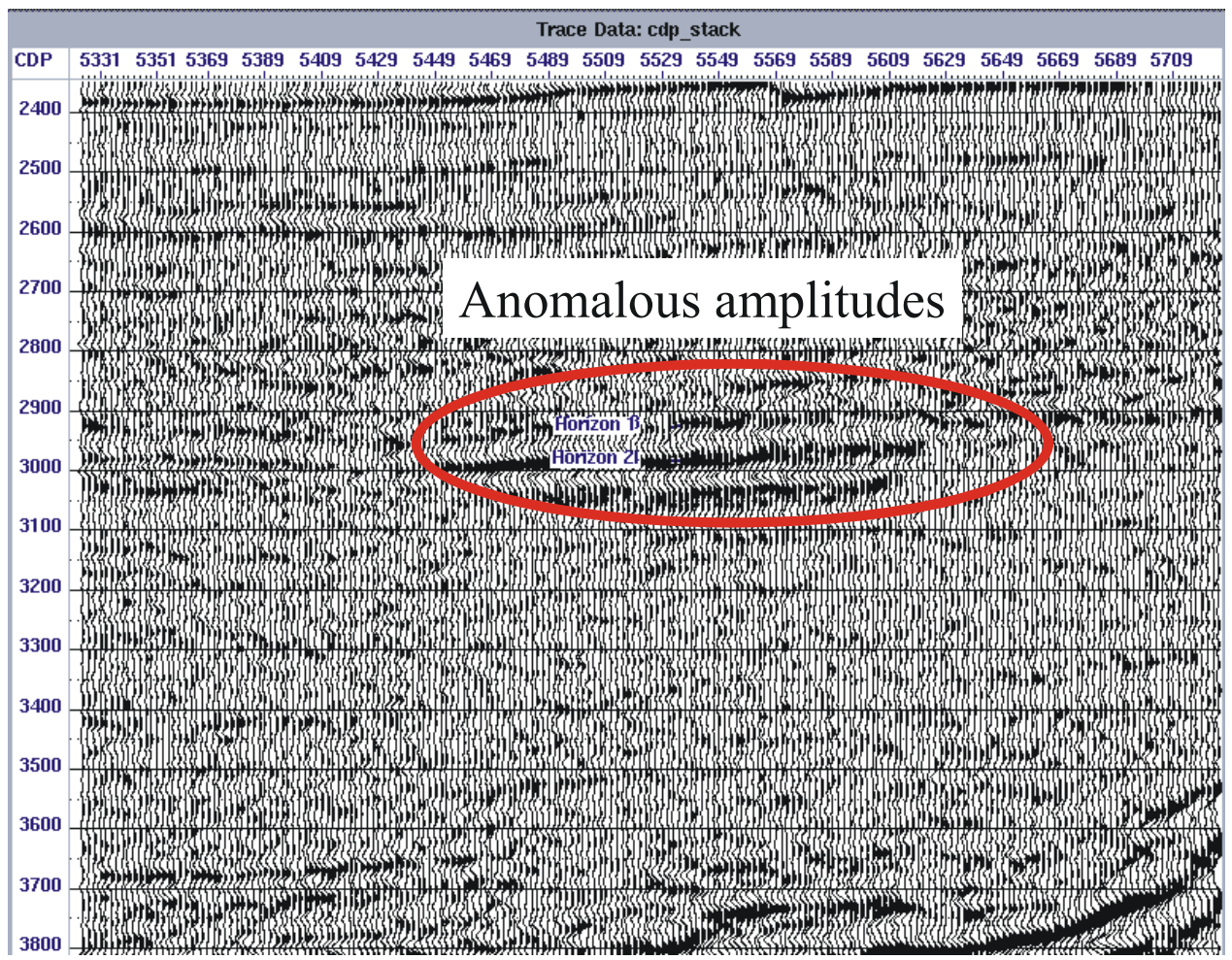

Fig. 13. Full stack of $2 \mathrm{D}$ data extracted from a $3 \mathrm{D}$ volume across the Assynt prospect well 204/18-1. 

(a) CDP 5401
(b) CDP 5525
(c) CDP 5621

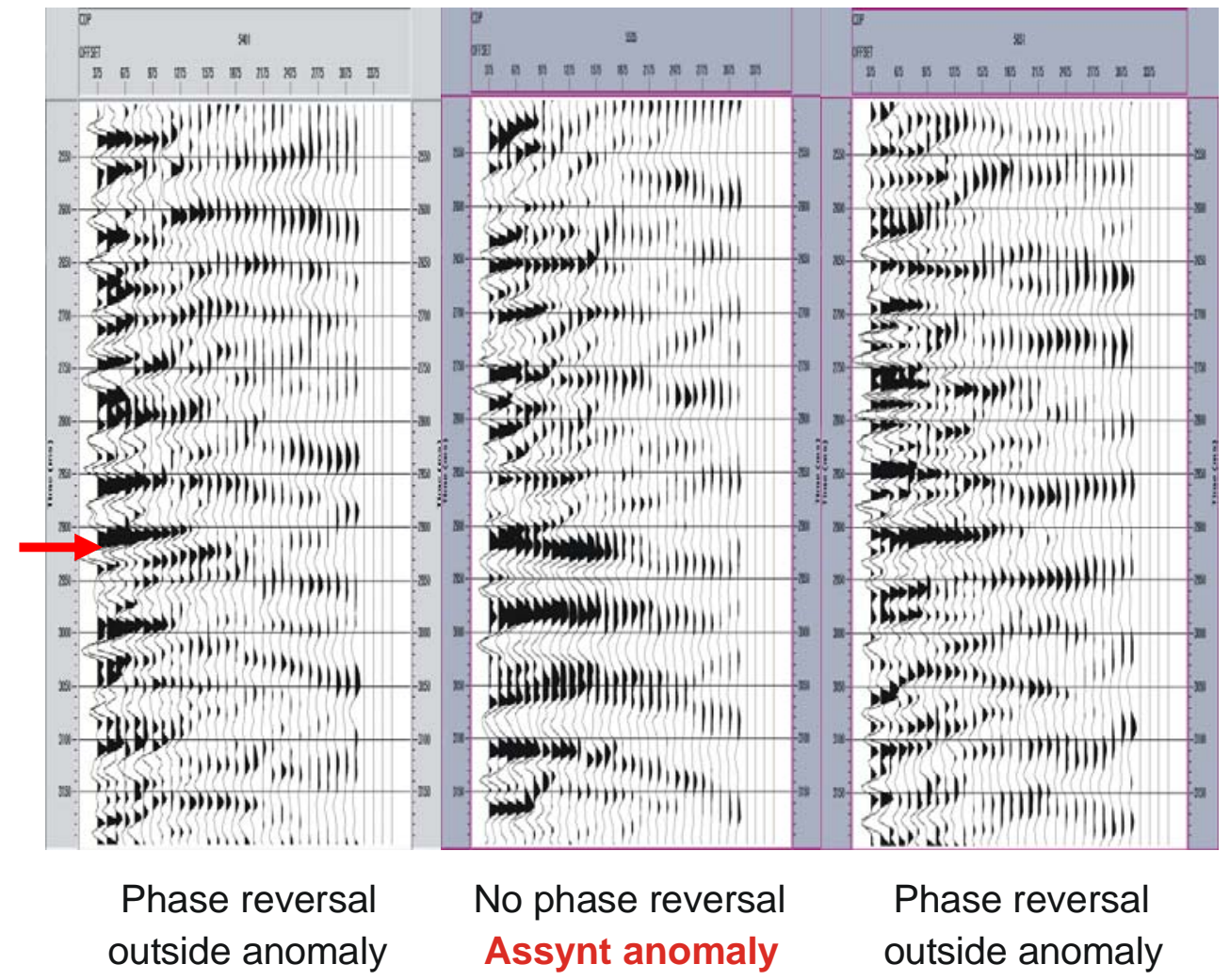

Fig. 14a, b and c. CDP gathers from the 204/18-1 well primarily showing amplitude decrease with offset.

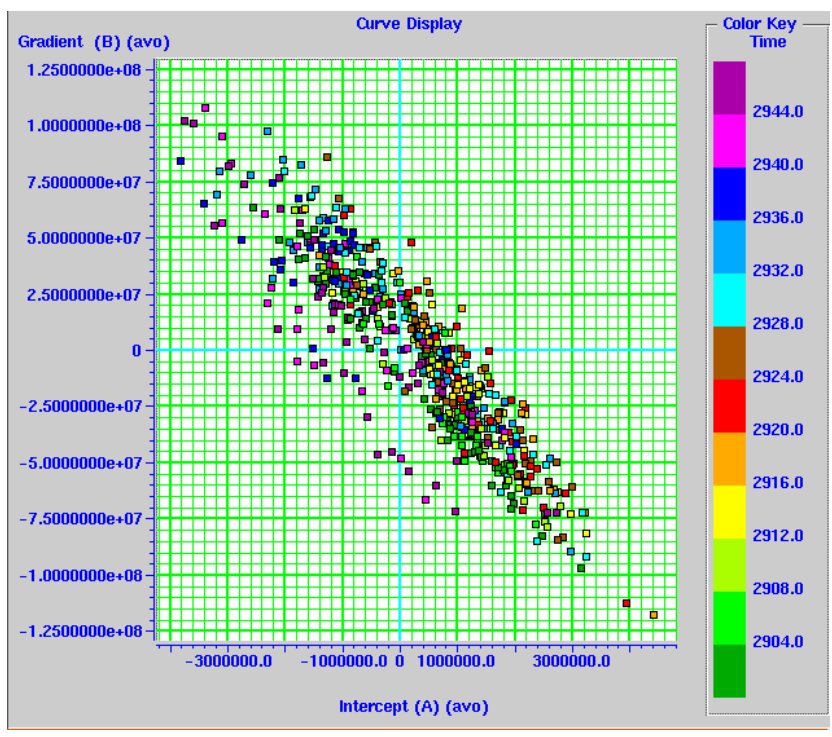

Fig. 15. AVO cross-plot for 204/18-1 well showing typical Class I type AVO for the amplitude anomaly. 


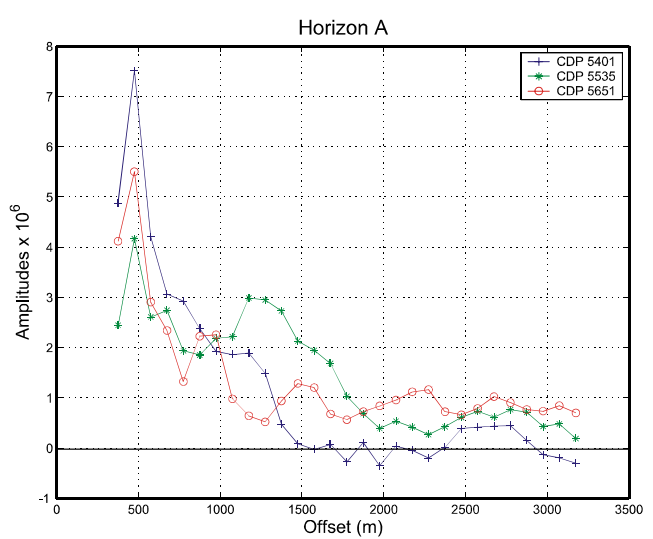

Fig. 16. Comparison of amplitude variations with offset for horizon A from three CDPs.

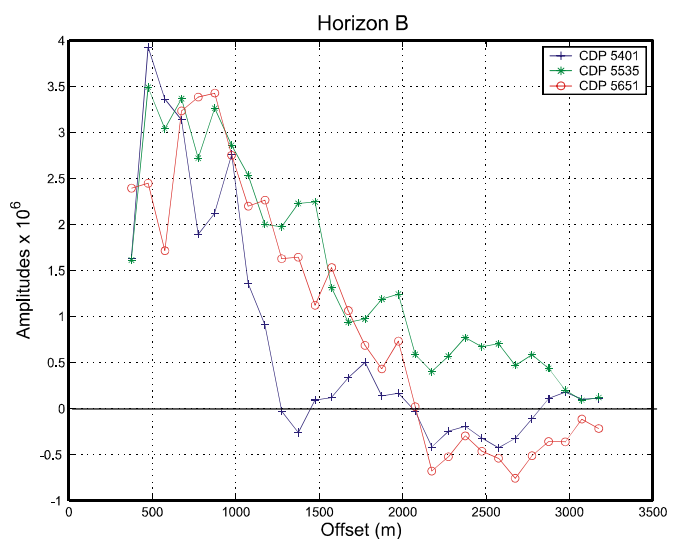

Fig. 17. Comparison of amplitude variations with offset for horizon B from three CDPs.

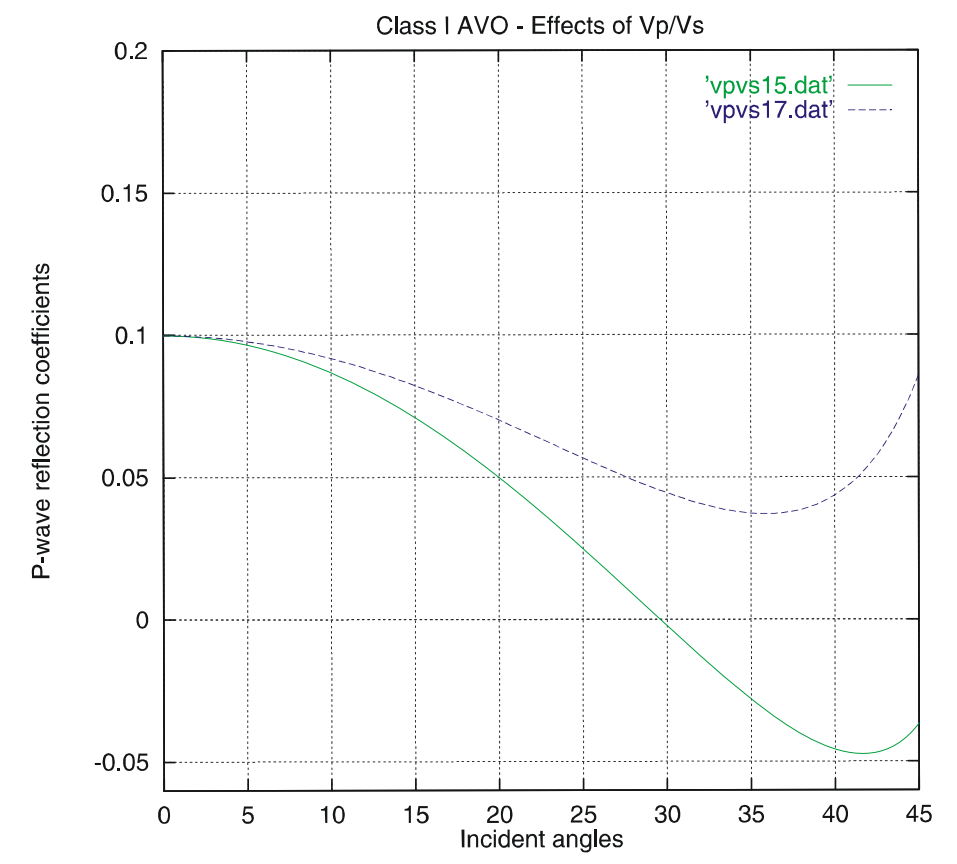

Fig. 18. Effects of $\mathrm{Vp} / \mathrm{Vs}$ in reservoir layers: an increase in $\mathrm{Vp} / \mathrm{Vs}$ will shift the zerocrossing to larger offset, resulting in no phase reversal. Solid green line $\mathrm{Vp} / \mathrm{Vs}=1.5$ and dashed blue line $\mathrm{Vp} / \mathrm{Vs}=1.7$. 

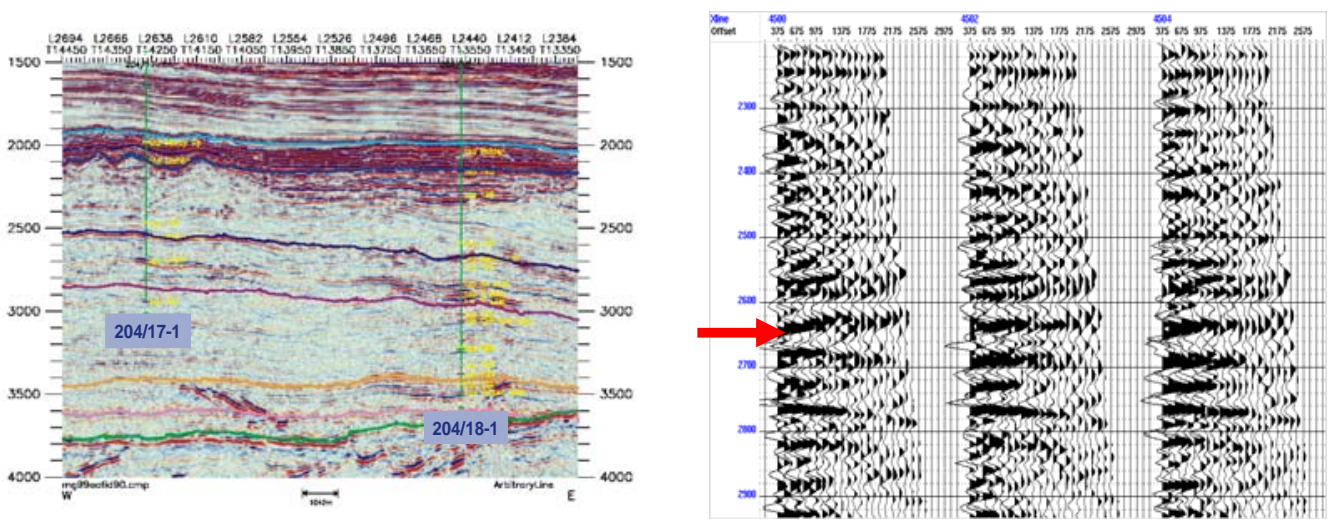

Fig. 19. Location of wells 204/17-1 and 204/18-1. CDP gathers from well 204/17-1 showing that amplitudes at the anomaly $(2660 \mathrm{~ms})$ decrease with offset.
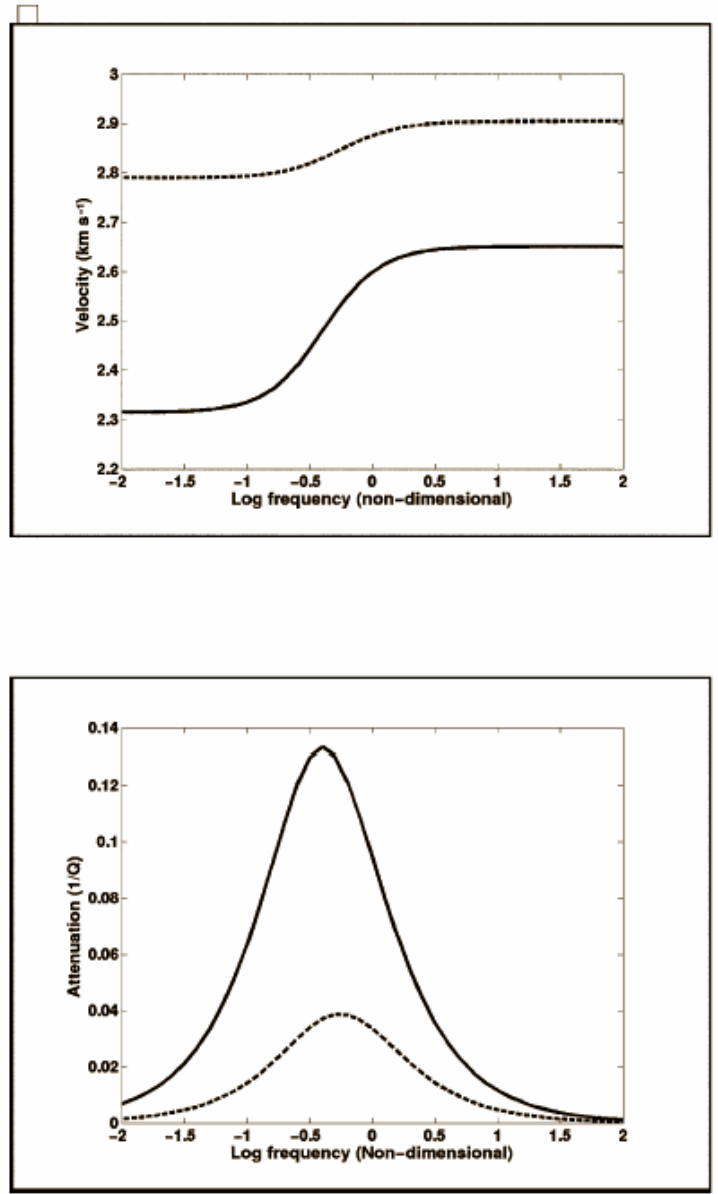

Fig. 20. Predicted velocities and attenuation for model 1 of Table 1 as a function of non-dimensional frequency $\omega \tau$ ( $\tau$ is the relaxation time, $\tau=20 \mu$ s and $\omega$ is angular frequency). Top $-\mathrm{P}$ wave velocities and Bottom - P-wave attenuation. Dashed lines correspond to water saturation and solid lines to gas saturation (see Table 1 for parameters). The figure is taken from Chapman et al. (2006). 


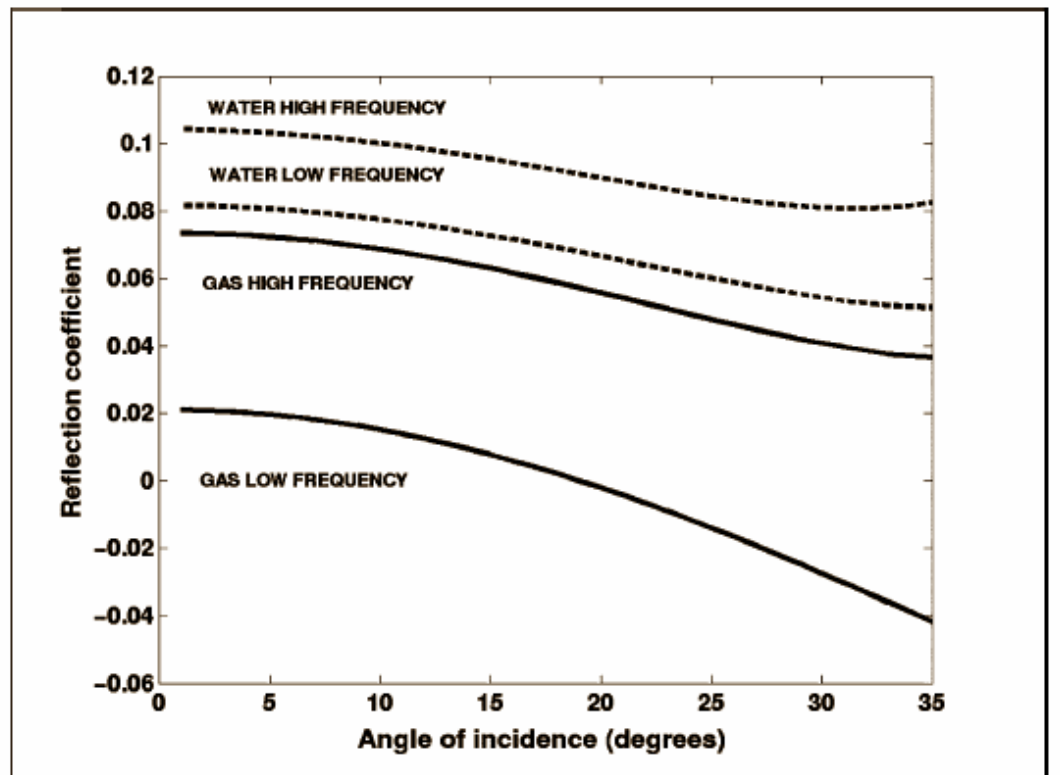

Fig. 21. Variation of P-wave AVO with fluid saturation in the high and low frequency limits for a typical Class I type AVO (Model 1, see parameters used in the computations in Table 1). The figure is taken from Chapman et al. (2006).

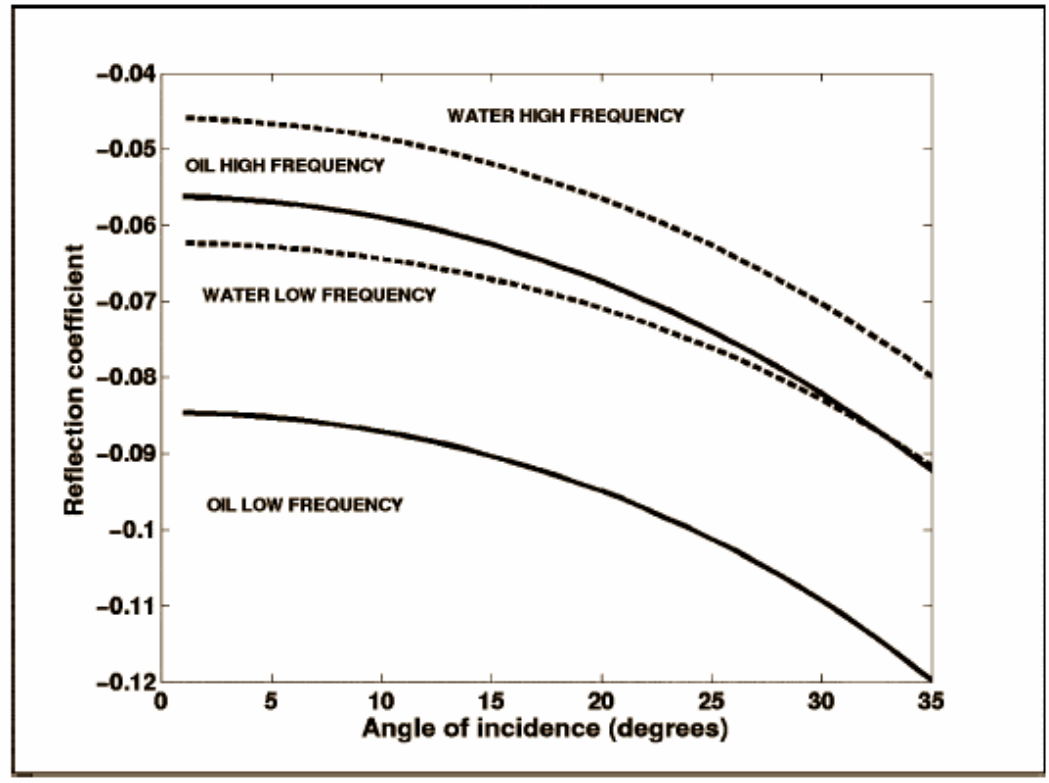

Fig. 22. Variation of P-wave AVO with fluid saturation in the high and low frequency limits for a typical Class III type AVO (Model 2, see parameters used in the computations in Table 1). The figure is taken from Chapman et al. (2006). 

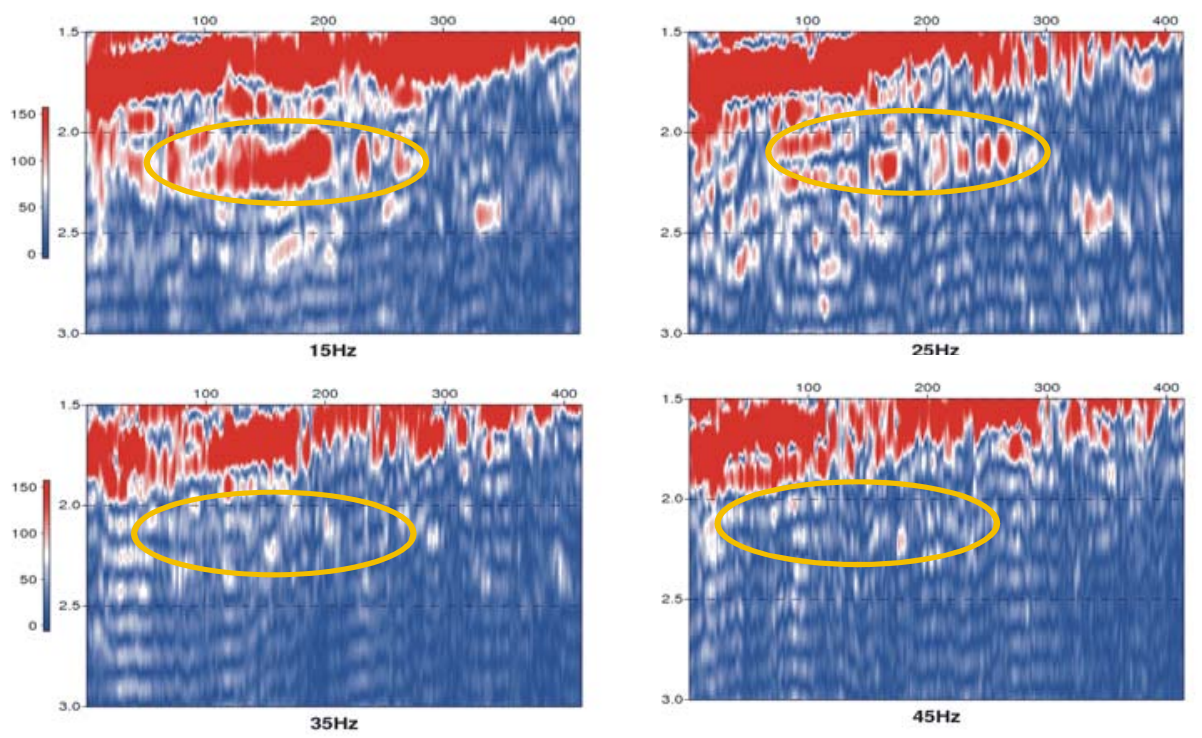

Fig. 23. Selected isofrequency sections of the stacked seismic data from Foinaven. We can see a systematic decrease of amplitudes with frequency in the marked target Areas, which is qualitatively consistent with the prediction of Fig. 22 for the Class III AVO. The vertical axis is two-way travel time in seconds.
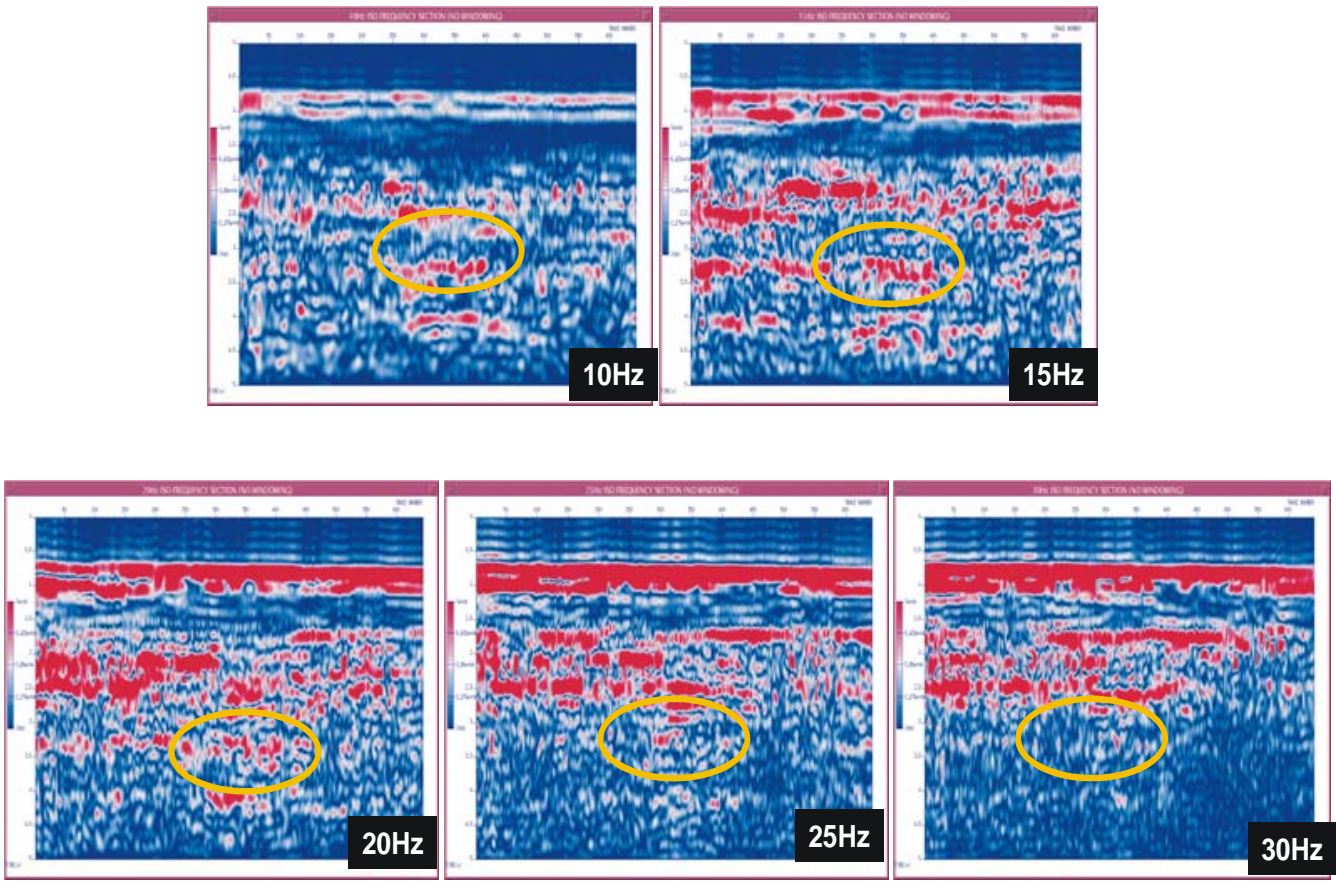

Fig. 24. Selected iso-frequency sections of the stacked seismic data from Laggan. We can see a systematic decrease of amplitudes with frequency in the marked target areas which is qualitatively consistent with the prediction of Fig. 22 for the Class III AVO. The vertical axis is two-way travel time in seconds. 

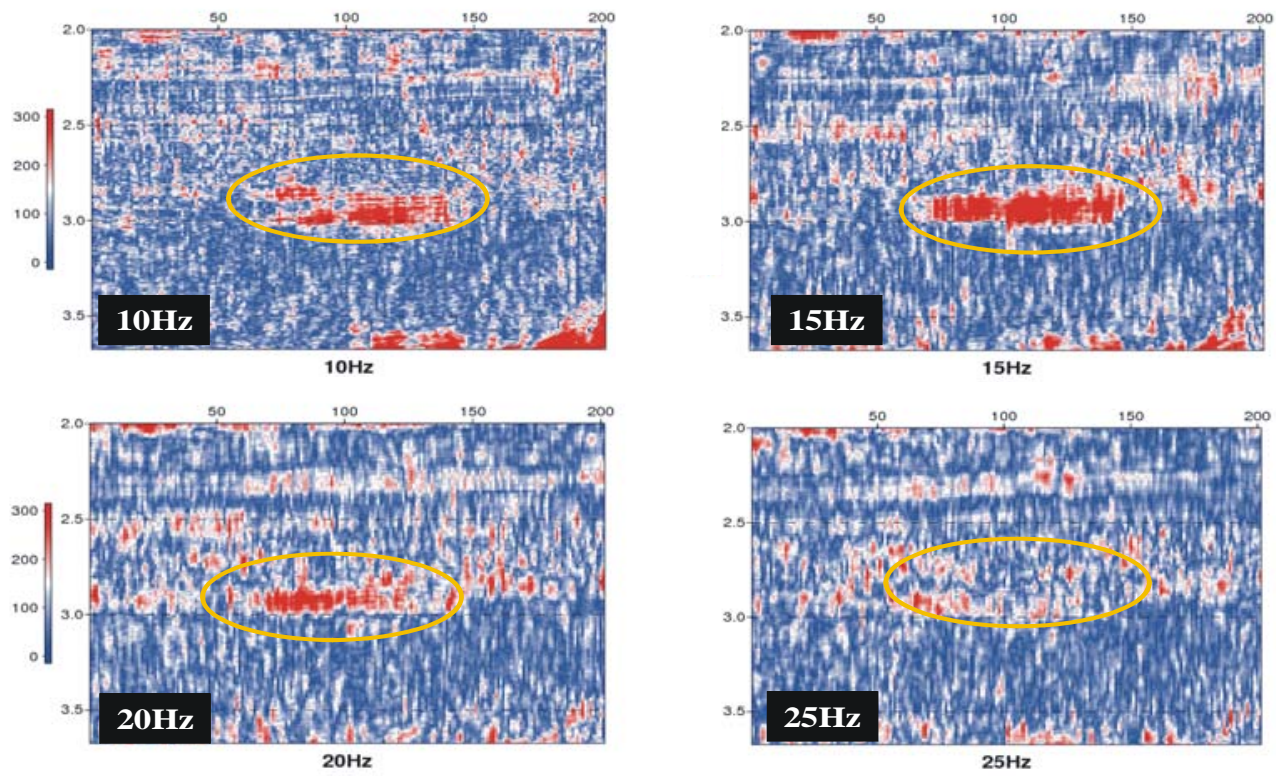

Fig. 25. Selected iso-frequency sections of the stacked seismic data from Assynt prospect. We can observe that the amplitudes in the marked area change markedly from an increase with frequency between $10 \mathrm{~Hz}$ and $15 \mathrm{~Hz}$, to a decrease with frequency between $15 \mathrm{~Hz}$ to $20 \mathrm{~Hz}$. This suggests that the Assynt anomaly is indeed concentrated on the very low frequency range over a very narrow frequency band. The increase of amplitudes with frequency is consistent with the prediction shown in Fig. 21 for Class I type AVO, but the sudden decrease thereafter cannot be fully explained. The vertical axis is two-way travel time in seconds. 